\title{
Apical Canal Transportation after Instrumentation with Two New Rotary Files; A comparative Study with Micro CT
}

\author{
Wisam Sakr
}

Follow this and additional works at: https://researchrepository.wvu.edu/etd

\section{Recommended Citation}

Sakr, Wisam, "Apical Canal Transportation after Instrumentation with Two New Rotary Files; A comparative Study with Micro CT" (2016). Graduate Theses, Dissertations, and Problem Reports. 6557. https://researchrepository.wvu.edu/etd/6557

This Thesis is protected by copyright and/or related rights. It has been brought to you by the The Research Repository @ WVU with permission from the rights-holder(s). You are free to use this Thesis in any way that is permitted by the copyright and related rights legislation that applies to your use. For other uses you must obtain permission from the rights-holder(s) directly, unless additional rights are indicated by a Creative Commons license in the record and/ or on the work itself. This Thesis has been accepted for inclusion in WVU Graduate Theses, Dissertations, and Problem Reports collection by an authorized administrator of The Research Repository @ WVU. For more information, please contact researchrepository@mail.wvu.edu. 


\title{
Apical Canal Transportation after Instrumentation with Two New Rotary Files; A comparative Study with Micro CT
}

\section{Wisam Sakr, D.D.S.}

Thesis Submitted to the School of Dentistry of Robert C. Byrd Health Sciences Center at West

Virginia University in partial fulfillment of the requirements for the degrees of

\author{
Masters of Science
}

In

Endodontics

Richard Jurevic, DDS, PHD; Chair

Michael Bagby, DDS, PHD, MS

Anthony T. Borgia, DDS, MHA

Department of Endodontics

Morgantown, West Virginia

2016

Keywords: apical Canal transportation, Trushape, EdgeEvolve, microCT

Copyright 2016 Wisam Sakr D.D.S 


\title{
Abstract \\ Apical Canal Transportation after Instrumentation with Two New Rotary Files; A comparative Study with Micro CT
}

\author{
Wisam Sakr, D.D.S.
}

$\underline{\text { Introduction }}$

Excessive dentin removal in a single direction within the canal causes canal transportation. A study by Peters OA has shown that the canal transportation is highest apically. A number of cleaning and shaping principles have been previously suggested and should be followed to achieve optimum results. These principles include the developing of a continuously tapering funnel from the coronal access cavity to the root apex, following the original canal shape and maintaining the apical foramen in its original spatial relationship both to the periapical tissues and to the root surface. The aim of this study is to construct detailed three-dimensional images of root systems and measure the changes in canal anatomy, using TRUShape ${ }^{\circledR}$ 3D Conforming Files, and EdgeEvolve ${ }^{\mathrm{TM}}$ files.

\section{$\underline{\text { Materials and Methods }}$}

Thirty maxillary molars were mounted at the cemento-enamel junction in modified poly-propylene 50 $\mathrm{ml}$ centrifuge tubes using a radiolucent methyl methacrylate acrylic resin. All specimens were preoperatively scanned with microCT-40. Images from the microCT-40 were transferred to Image J® image analyzing software to assess the initial dentin thickness measured $1 \mathrm{~mm}$ from the apex. Canals were then instrumented to length with both file systems. Each specimen was measured after canal preparation in a manner identical to the pre-instrumentation measurement. Wilcoxon Rank Sum test was used to determine statistical variance between procedures. Both instruments resulted in no procedural errors.

$\underline{\text { Results }}$

Transportation scores were $95 \pm 60 \mu \mathrm{m}$ for TRUShape and $120 \pm 70 \mu \mathrm{m}$ for EdgeEvolve. The overall canal transportation results by TRUShape were significantly lower $(\mathrm{p}<.05)$. However, both file systems had similar centric ratios with no statistically significant difference.

\section{$\underline{\text { Conclusion }}$}

The amount of remaining dentin after shaping depends on canal transportation, and, in return, this number depends on canal curvature. Therefore, it is difficult to compare the present results with data from other studies; however, between the two instruments tested under present conditions, TRUShape ${ }^{\circledR}$, resulted in less canal transportation and more remaining dentin in the canal walls. It continues to be a matter of debate if the amount of preserved structure will translate into enhanced clinical outcomes. 


\section{Dedications}

To my parents, Hassan and Magda, for their nonstop, unconditional love and support. No matter how far away they are or how frustrated I am or how frustrated they are at times, I have always benefited from their advice, their support and their experience and they are always there for me.

To my brother Sharif who has always encouraged me to pursue my dreams, and to try harder, and to always persevere no matter what or how difficult things may be. 


\section{Acknowledgements}

Dr. Anthony Tom Borgia: Thank you for the last two years of mentorship. I enjoyed our conversations and friendship. I am so grateful you gave me a chance to be part of WVU family.

Dr. Keith Hildebrand: Thank you for all the clinical tricks you have shown me. I am glad you took the Chair position at WVU. I feel you will guide the WVU endodontic department in the right direction

Dr. Marvin Leah Speer: Thank you for making me a better practitioner and sharing all your knowledge with me. You have been of great help to me.

Dr. Richard Jurevic: Thank you so much for your support and help with my research. I truly could not have done it without you.

Dr. Takashi Komabayashi: Thank you for helping me with the literature and preparing for the boards.

Dr. Mark Byron: Thank you for spending every Friday coming to school to help the residents, students, and the department. You have my utmost respect and admiration. Thank you for sharing your clinical tricks and the business side of endodontics with me.

Dr. Michael Bagby: Thank you for being a member of my research committee and helping me with my thesis project. I could not have done it with your support.

Dr. Patrick Cushing: Thank you for the statistical analysis. I really enjoyed the conversations we had.

Dr. Yoshio Yahata: Thank you for helping me on my project. Good luck with your future plans.

Dr. Emma Hunter: I am so lucky to have you as my co-resident and as a dear friend. For the past two years, we have pushed each other, learned from each other, and laughed together. This definitely made residency a better place. Good luck with everything. I wish you the best because you deserve to be the best. Hope we always stay connected.

Dr. Pejman Parsa: Thank you for the one day boot camp you gave me! You know how every little thing helps. I really enjoyed going to get coffee \& donuts.

Dr. Andy Xu: Thank you so much for always helping me out with hard cases and your advice. I really could not have done it without you. I really enjoyed going to number one buffet. I really miss those days.

Dr. Stephen Fragale: Thank you for helping me out with all the computer trouble I had this past year and you clinical input on cases. It was a lot of fun going on trips together.

Dr. Shean Horan: Thank you for your clinical advice and going on trips together. I will definitely miss those days. 
Mehran Malakpour: Thank you for all your help with my research and those long nights working in the clinic.

Thank you to all the faculty and staff at WVU for supporting me and our Endodontic Department. 


\section{List of Tables}

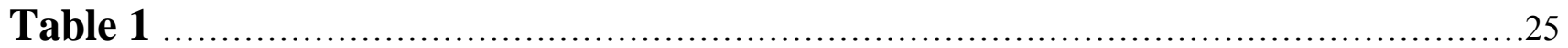




\section{List of Figures}

Figure 1. A schematic drawing of TRUShape rotary files sizes \#20,\#25,\#30, and \#40 .06v

Figure 2. A schematic drawing showing the unique $S$-shape design of Trushape and the envelope of motion it

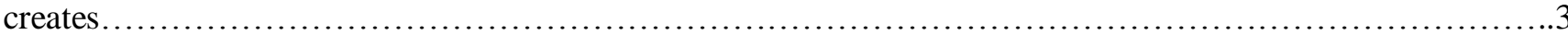

Figure 3. A schematic representation of cross-sectional canal shapes before and after preparation with each file

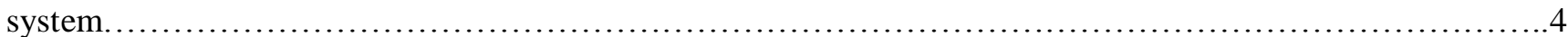

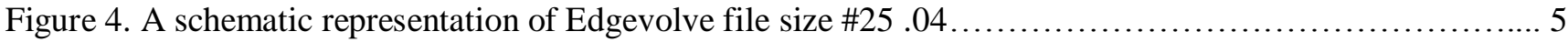

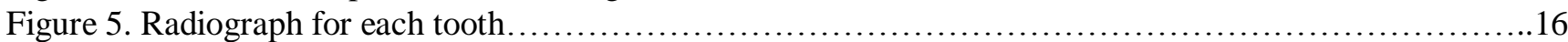

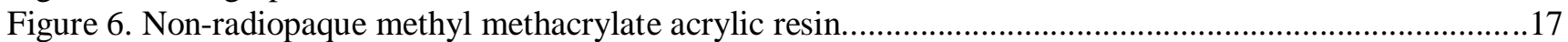

Figure 7. Tooth was mounted in the tube and buccal surface was marked...................................................18

Figure 8. MicroCT-40 (Scanco Medical, Switzerland) ................................................................................ 18

Figure 9a. Tooth mounted centrifuge tube was inserted into a sample holder for mCT measurement............19

Figure 9b. The sample holder was placed on the Specimen table inside the chamber of the Micro CT - $40 \ldots \ldots . . .19$

Figure 10. Representative drawing of tooth sections showing how transportation, centering ratios, and largest

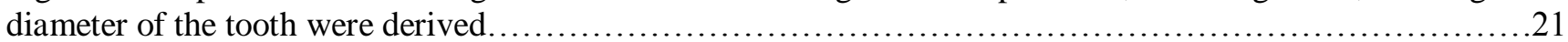

Figure 11. Micro CT; Before preparation showing X1 and after preparation showing X2 ..................22

Figure 12. Diagrammatic illustration of the respective distributions of transportation scores for EdgeEvolve ${ }^{\mathrm{TM}}$

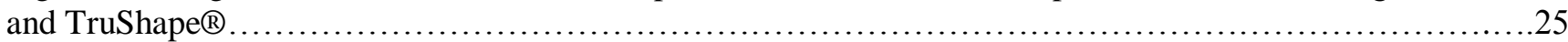

Figure 13. Diagrammatic representation of the respective distributions of the Wilcoxon scores for transportation. The diamond is the mean score $\&$ the straight line is the median score.......................26 Figure 14. Diagrammatic illustration of the respective distributions of centering ratio scores for EdgeEvolve $\mathrm{e}^{\mathrm{TM}}$

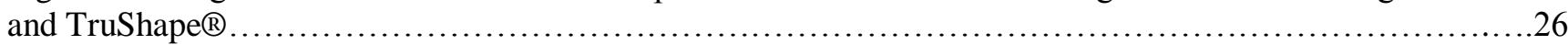
Figure 15. Diagrammatic representation of the distributions of the Wilcoxon scores for centering ratios. The

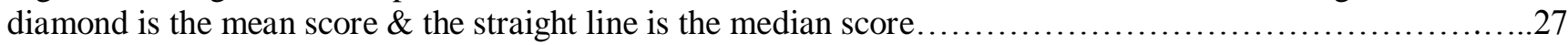

Figure 16. An illustration of TRUShape ${ }^{\circledR}$ preparation with minimal transportation..........................28

Figure 17. An illustration of EdgeEvolve ${ }^{\mathrm{TM}}$ preparation showing more evident transportation..................28 Figure 18. Cyclic fatigue rates for EdgeEvolve ${ }^{\mathrm{TM}}$, Vortex Blue®, Sybron K3X®F, Sybron K-3®, GT Series $\mathrm{X} \circledast$, ProTaper ${ }^{\circledR}$, and Sequence ${ }^{\circledR}$ Files.... 


\section{List of Symbols, Abbreviation, or Nomenclature}

Millimeters - mm

Sodium hypochlorite - $\mathrm{NaOCl}$

Ethylenediameteraacetic acid - EDTA

Working Length - WL

Institutional Review Board - IRB

Master Apical File Size - MAFS

Randomized Clinical Trial - RCT

Chlorhexidine - CHX

Nickel Titanium - NiTi

Residual dental thickness - RDT

Micrometer - $\mu \mathrm{m}$ 


\section{Table of Contents}

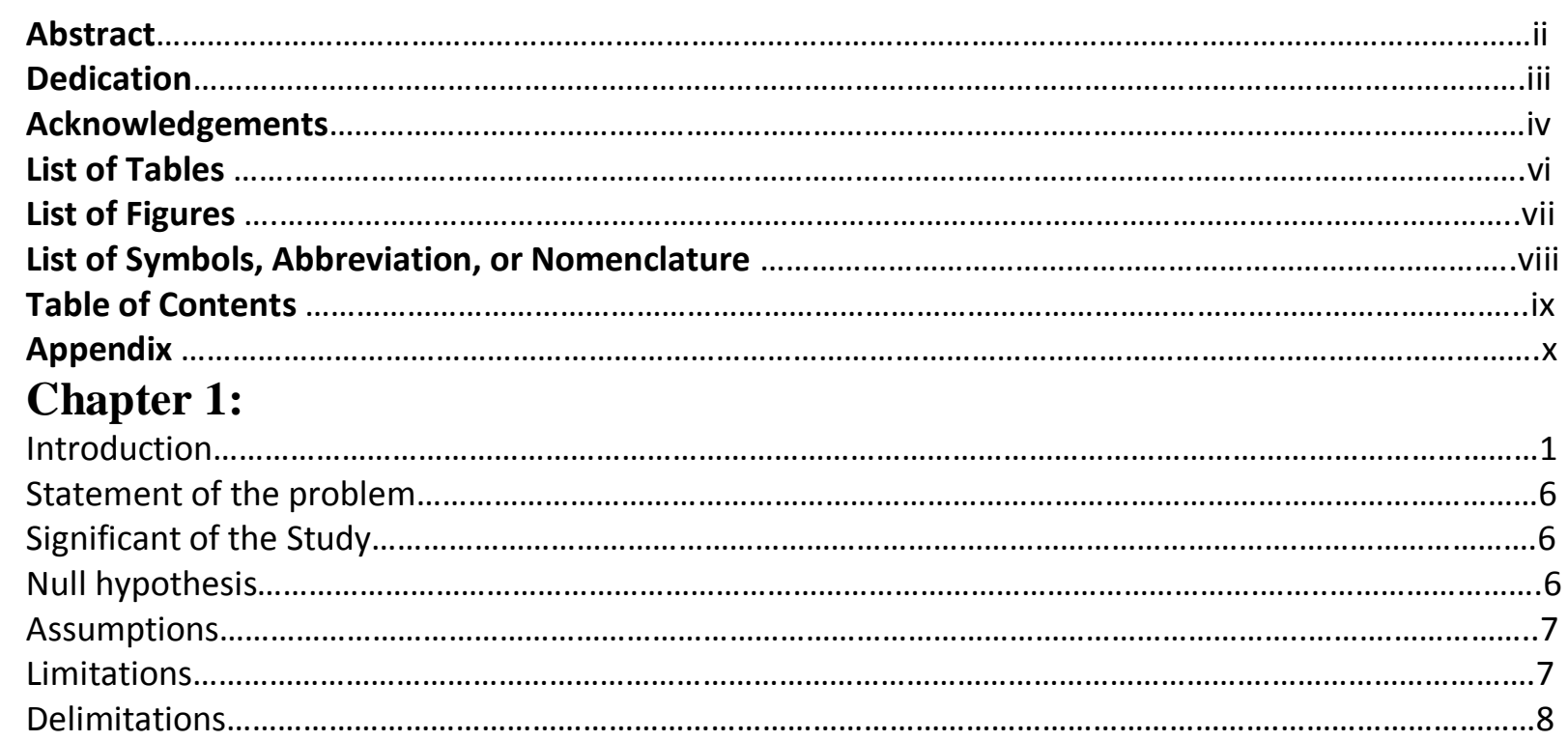

\section{Chapter 2:}

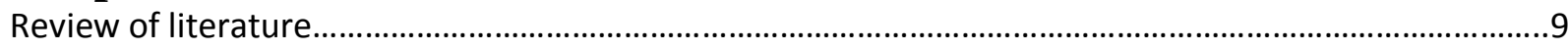

Chapter 3:

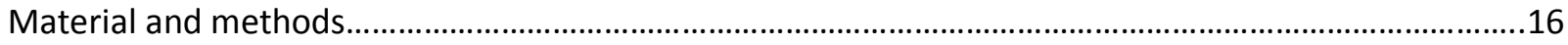

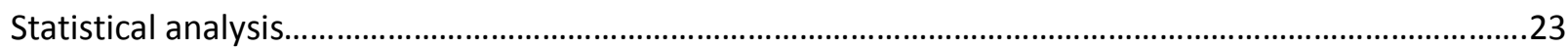

Chapter 4:

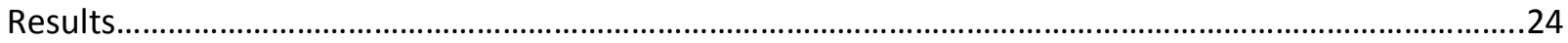

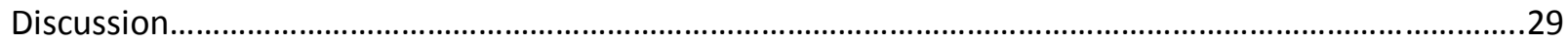

Chapter 5:

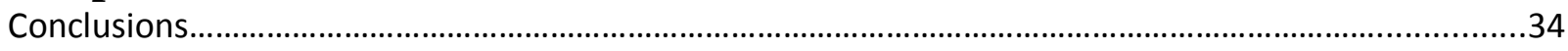

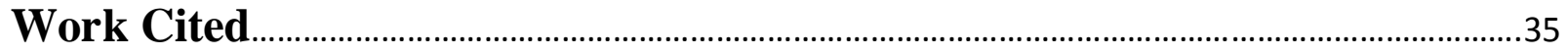




\section{Appendix}

Institutional Review Board Exemption Approval Letter...........................................45

Table of values for Transportation and Centering ratio............................................... 


\section{Chapter 1}

\section{Introduction}

The goal of root canal therapy is to clean and shape the root canal system in such a way that would allow for the total eradication of microorganisms. Cleaning and shaping is considered to be the most significant step behind success or failure in endodontic therapy. Proper cleaning and shaping is achieved by not only the removal of inflamed/necrotic pulp tissue along with microorganisms and their toxins, but also allow adequate irrigation to reach the apical third of the root canal system to prepare for subsequent obturation. ${ }^{1,2}$

According to the Glossary of Endodontic Terms ${ }^{94}$ of the American Association of Endodontists transportation is defined as "removal of canal wall structure on the outside curve of the apical half of the canal due to the tendency of files to restore themselves to their original linear shape during canal preparation; may lead to ledge formation and possible canal perforation."

Regardless of the instrumentation technique, cleaning and shaping procedures invariably leads to dentin removal from canal walls. ${ }^{3}$ Root canal morphology changes during canal preparation, with these changes varying depending upon the technique employed. Canal transportation is defined as excessive dentin removal in a single direction within the canal rather than in all directions equidistantly from the center of the canal. ${ }^{4}$

A study by Peters and others has shown canal transportation to be found most frequently in the apical region. The mean scores in their study varied from 1.8 to $50 \mu \mathrm{m}$, and that apical transportation occurs mainly in an outward direction in relation to the greater curvature regardless of the instrumentation technique used. ${ }^{29}$ 
The maxillary first molar is the largest tooth in volume and the most complex tooth in root canal anatomy. ${ }^{14,15}$ The mesiobuccal root has generated more research and clinical investigation than any other tooth root. ${ }^{15,16}$ In general, a concavity exists on the distal aspect of the mesiobuccal root, which makes this wall thin. On average, curved mesiobuccal canals often have greater canal transportation than most other canals. ${ }^{14}$

Two new NiTi rotary systems just introduced into the market are TRUShape ${ }^{3}$ 3D Conforming files and EdgeEvolve ${ }^{\mathrm{TM}}$. All the following information about TRUShape ${ }^{\circledR}$ 3D Conforming file is from the DENTSPLY® website. TRUShape ${ }^{\circledR} 3 \mathrm{D}$ Conforming file (DENTSPLY® Tulsa Dental, Johnson City, TN, USA) has a unique S-shape design, allowing it to conform to areas of the canal larger than the nominal file size (Figure 1). This creates an envelope of motion that better disrupts biofilms for improved bacterial reduction (Figure 2). As a result, TRUShape 3D Conforming files results in the preservation of more dentinal structure while at the same time removing pulp and debris along the entire length of the root canal (Figure 3). They reportedly create a predictable apical shape with up to $32 \%$ less apical transportation than found in conventional ISO prepared canals and also remove up to $36 \%$ less dentin with superior overall shaping when compared to conventional ISO rotary files. 


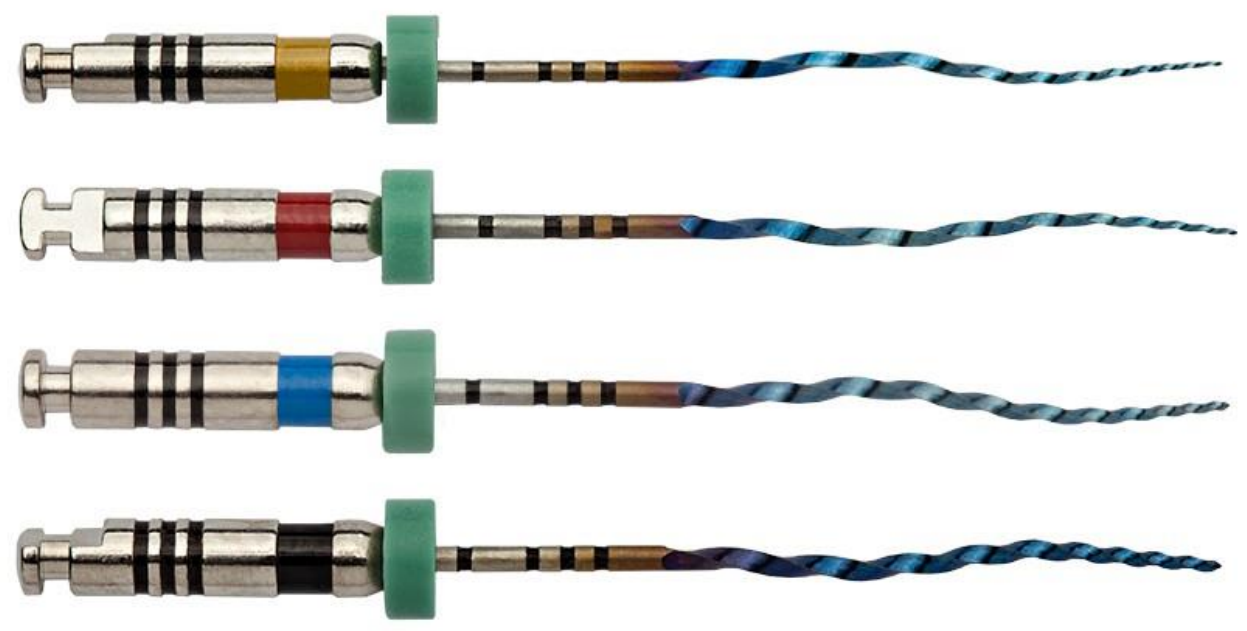

Figure 1. A schematic drawing of TRUShape rotary files sizes \#20,\#25,\#30, and \#40.06v.

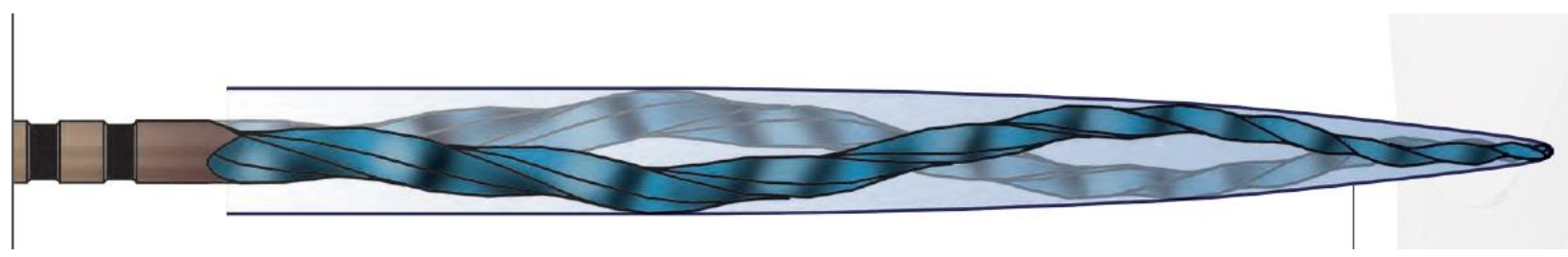

Figure 2. A schematic drawing showing the unique S-shape design of Trushape and the envelope of motion it creates. 


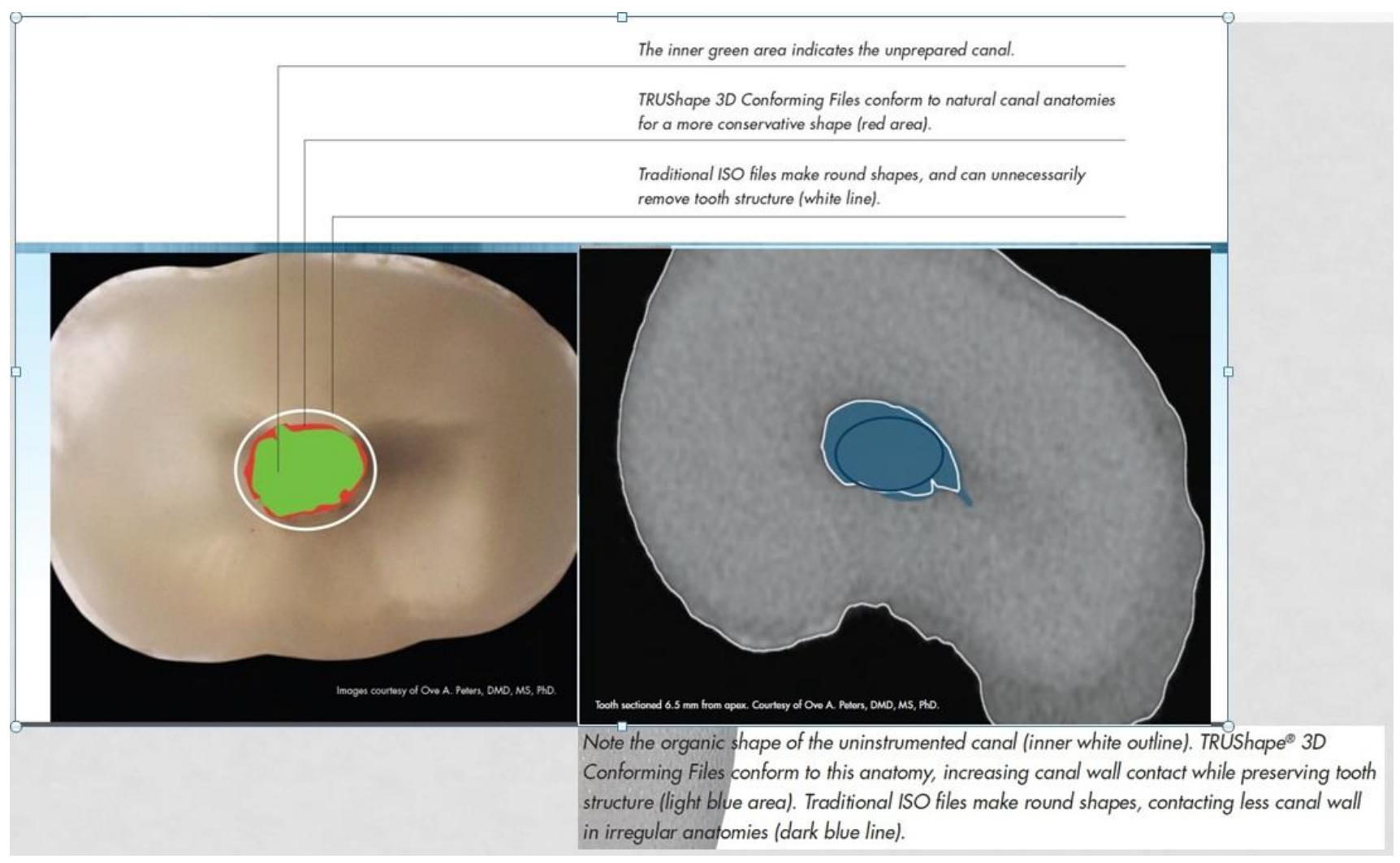

Figure 3. A schematic representation of cross-sectional canal shapes before and after preparation with each file system.

All of the following information about the EdgeEvolve ${ }^{\mathrm{TM}}$ is from EdgeEndo® website. According to the manufacturer, "EdgeEvolve ${ }^{\mathrm{TM}}\left(\right.$ EdgeEndo®) files are FireWire ${ }^{\mathrm{TM}}$ heat-treated and cryogenically tempered NiTi which makes the file's triangular cross section incredibly strong, flexible and efficient in cutting - while the open flutes provide superior debris removal (figure 4). The revolutionary strength and flexibility of the FireWire ${ }^{\mathrm{TM}}$ heat-treated NiTi offers smoother cutting and greater versatility. EdgeEndo® rotary files are known to be the most flexible files available in the market. Better flexibility without shape memory conserves apical anatomy. EdgeEvolve ${ }^{\mathrm{TM}}$ is so flexible that a 40/1.0 bends as easily as some 0.04 taper files. The unmatched flexibility allow for larger apex and tapers to shape canals. All EdgeEvolve ${ }^{\mathrm{TM}}$ files, including the 40/1.0 has a maximum 
$1 \mathrm{~mm}$ flute diameter. This conservative flute design and taper is purported to preserve more dentin than other files."

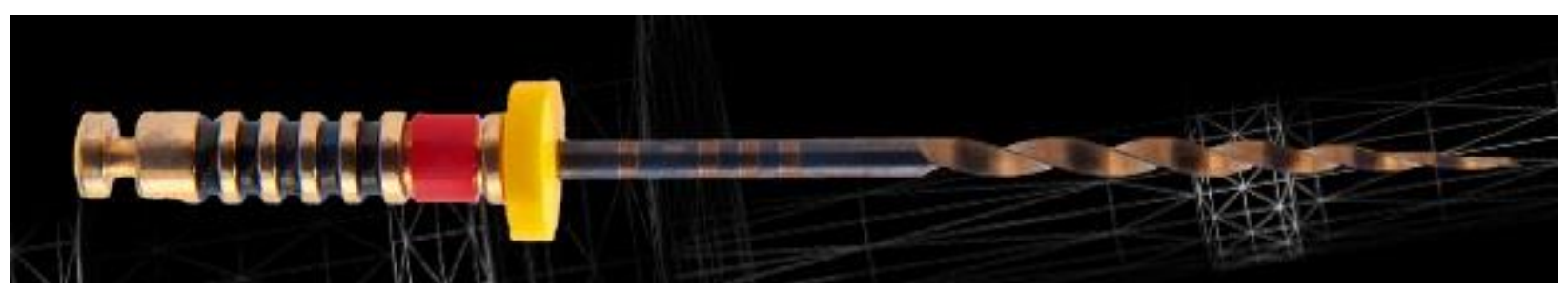

Figure 4. A schematic representation of Edgevolve file size \#25 .04

Several methodologies have been proposed to assess the action of endodontic instruments on canal walls. Some of the methods used include radiographic imaging, cross sectioning, and longitudinal cleavage of teeth. More recently, a number of studies have used micro CT imaging to look at the effect of various instrumentation techniques and their efficiencies. ${ }^{5-9}$ Newer micro CT machines have vastly improved resolution and minimize projection errors from which earlier micro CT suffered. ${ }^{10}{ }^{11}$ Micro CT has been particularly useful for studies on endodontic instrumentation because it permits both two dimensional and three dimensional evaluations of root canal geometry, and quantitative measurements of dentin removal from canal walls. ${ }^{12}$ Furthermore, micro CT also allows noninvasive evaluation of the root canal system and its morphologic characteristics in a detailed and accurate manner without destruction of the tooth. ${ }^{13}$ 


\section{Statement of the Problem}

It is known that canal transportation occurs with rotary files, but the amount of apical canal transportation that TRUShape ${ }^{\circledR}$ 3D Conforming files \& EdgeEvolve ${ }^{\mathrm{TM}}$ files cause in maxillary molars is unknown. Another unknown is whether or not the new TRUShape ${ }^{\circledR}$ 3D Conforming files can conform to unconstrained spaces while respecting constrained spaces with their innovative envelope of motion and ultimately cause less apical transportation than EdgeEvolve ${ }^{\mathrm{TM}}$ files.

The aim of this study is to construct detailed 3 dimensional images of root canal systems and measure the changes in canal anatomy, i.e. transportation using TRUShape ${ }^{\circledR} 3 \mathrm{D}$ Conforming files and EdgeEvolve ${ }^{\mathrm{TM}}$.

\section{Significance of the Study}

The results of this study will give clinicians a better understanding of the two file systems tested and whether one system maintains the original canal anatomy of the MB roots in maxillary molars better than the other. This may have an impact on the file system that a clinician chooses for his curved, narrow, flat and complex canal systems.

\section{Null Hypothesis Tested}

There is no difference between both TRUShape ${ }^{\circledR}$ 3D Conforming files and EdgeEvolve ${ }^{\mathrm{TM}}$ files in regards to apical canal transportation and centric ability. 


\section{Assumptions}

- Maxillary mesiobuccal roots have a ribbon like flat and narrow canal with an accentuated curvature.

- The "danger zone" is located in the distal wall of the coronal section of maxillary mesiobuccal roots.

- Regardless of the instrumentation technique, canal transportation is inevitable.

- Apical transportation occurs mainly in an outward direction in relation to the greater curvature regardless of the instrumentation technique used.

- Canal transportation is highest apically.

- TRUShape ${ }^{\circledR}$ 3D Conforming files create a predictable apical shape with less apical transportation than conventional ISO prepared canals.

- EdgeEvolve ${ }^{\mathrm{TM}}$ conservative flute design and taper preserves more dentin than other files.

- Measurement by micro-CT is the most accurate way to determine dentin removal utilizing current technology.

\section{Limitations}

- This is an in-vitro study of a clinical procedure; therefore, the results may not correlate to an in vivo condition.

- Small sample size.

- Root canal anatomy can be widely varied from tooth to tooth.

- Lengths of the roots are not standardized.

- Degree of curvature of the mesiobuccal canals vary. 


\section{Delimitations}

- Each tooth was examined radiographically preoperatively with mesial to distal and buccal to lingual views.

- All roots selected preoperatively have curvatures between $11^{\circ}$ to $35^{\circ}$.

- All teeth were accessed by one clinician in the same systematic approach utilizing identical methods, thereby keeping procedures as consistent as possible.

- The crowns were maintained to simulate, as closely as possible, the clinical endodontic practice, in which the interference of cervical dentin projections creates tensions on the files during root canal instrumentation.

- The use of micro CT is a non-destructive way for measurement. 


\section{Chapter 2}

\section{Review of the Literature}

1. Anatomy of the mesiobuccal root and curvature

2. Transportation

3. Procedural errors

4. Apical enlargement to reduce the microbial load

5. Larger apical preparation to promote irrigant efficacy

6. Residual dental thickness (RDT)

\section{Anatomy of the mesiobuccal root and curvature}

The maxillary first molar is the largest tooth in volume and the most complex tooth in root canal anatomy. ${ }^{14,15}$ The mesiobuccal root has generated more research and clinical investigation than any other tooth root. ${ }^{15,16}$ In general, a concavity exists on the distal aspect of the mesiobuccal root, which makes this wall thin. On average, curved mesiobuccal canals often have greater canal transportation than most other canals. ${ }^{14}$

Kuttler found that the average foramen to apex distance in all types of permanent teeth was 0.51 $\mathrm{mm} .{ }^{17}$ Green found the average distance from the apex to be $0.4 \mathrm{~mm}$ in the mesiobuccal root of maxillary molars. ${ }^{18}$ Palmer et al observed that canals in more than $50 \%$ of teeth sampled exited greater than $1 \mathrm{~mm}$ and some up to $2 \mathrm{~mm}$ short of the apex. ${ }^{19}$ In a more recent study, the distance between the physiologic and anatomic root apices in the mesiobuccal root of maxillary first and maxillary second molars has been measured between $0.78 \mathrm{~mm}$ and $0.82 \mathrm{~mm}$, for the buccal canal and $1.53 \mathrm{~mm}$ and 1.42 $\mathrm{mm}$ for the lingual canal, respectively. ${ }^{20}$ There is a clinical necessity to limit orthograde instrumentation short of the radiographic apex. ${ }^{21}$ 
An in vivo study found radiographically that the distribution of main canals in the mesiobuccal root of maxillary first molars to be $19.3 \%, 77.2 \%$, and $3.1 \%$ for mesiobuccal roots having one, two, and three canals, respectively. ${ }^{22}$ This compares with $20 \%, 79.8 \%$, and $1.1 \%$ being found in one, two, and three canals, respectively. ${ }^{21}$ An ex vivo micro-computed tomography study also compared with similar results showing $20 \%$ incidence of one canal and $80 \%$ incidence of two canals in the mesiobuccal root.$^{23}$ Different methods of analysis, however, can affect results, as seen in a recent evaluation of maxillary first molar anatomy using ex vivo clinical and cone beam computed tomography. $^{24}$

Using longitudinal grinding with a dye technique, Barrett found a 33\%, 61\%, and 6\% incidence of one, two, and three canals, respectively, in the mesiobuccal root of maxillary second molars ${ }^{89}$; whereas the clearing technique of Imura et al reported $33.4 \%$ with one canal and $66.3 \%$ of roots with two canals ${ }^{25}$. In another study the results were $38.1 \%, 60.3 \%$, and $1.6 \%$ for one, two, and three canals, respectively. $^{21}$

\section{Transportation}

Regardless of the instrumentation technique, cleaning and shaping procedures invariably lead to dentin removal from canal walls. ${ }^{3}$ Root canal morphology changes during canal preparation with these changes varying depending on the technique employed. Canal transportation is defined as excessive dentin removal in a single direction within the canal rather than in all directions equidistantly from the main tooth axis causes. ${ }^{4}$ According to Schilder transportation of the apical foramen is defined as moving the position of the canal's physiologic terminus to a new iatrogenic location on the external root surface. ${ }^{3}$ 
A Study by Peters and others has shown canal transportation to be found most frequently in the apical region. The mean scores in their study varied from 1.8 to $50 \mu \mathrm{m}$. And that apical transportation occurs mainly in an outward direction in relation to the greater curvature regardless of the instrumentation technique used. ${ }^{29}$

Another study by Peters and others compared TRUShape ${ }^{\circledR}$ files with an established fixed taper instrument; Vortex® files, in mesial roots of mandibular molars. ${ }^{30}$ According to this study transportation scores were averaged over root canal thirds and ranged from $53 \pm 19 \mu \mathrm{m}$ to $179 \pm 65 \mu \mathrm{m}$. Absolute canal transportation was significantly different $(\mathrm{P}<0.5)$ at each canal third. Moreover, TRUShape ${ }^{\circledR}$ removed less bulk dentin and left more dentin wall. This difference was significant and amounts to about $36 \%$ and $26 \%$ less dentin removed when preparing to apical sizes \#20 and \#30, respectively.

Apical transportation can be sub-divided into three types ${ }^{92}$ :

- Type I transportation is a minor movement of the physiologic apical foramen's position causing its iatrogenic relocation.

- $\quad$ Type II transportation is a moderate movement of the physiologic apical foramen's position causing a considerable iatrogenic relocation of the foramen on the external surface of the root. A larger communication with the periapical space exists, and attempt to create a more coronal shape may weaken or perforate the root.

- Type III transportation is a severe movement of the physiologic canal's position causing a significant iatrogenic relocation of physiologic foramen. 


\section{Procedural errors}

Different undesirable outcomes of apical preparations such as damage to the apical foramen, ${ }^{93}$ elbow formation, ${ }^{68}$ zip formation and perforation ${ }^{31}$ are proposed as possible outcomes of canal transportation. Perforation is defined as a communication between the root canal space and the external root surface, which results in irritation of the periapical tissues. Zip formation results in an elliptical shape at the apical terminus. Similar terms describing the shape of a zipped apical part of the root canal are an hourglass shape, ${ }^{68}$ a teardrop ${ }^{93}$ or a foraminal rip. ${ }^{95}$ Zipping is caused by using progressively larger and stiffer files to working length. It can result in a poorly cleaned root canal, which fails to provide a resistance form to compact gutta percha, and leads to obturation which is vertically overextended but internally under-filled. This contributes to leakage, infection and failure. ${ }^{92}$

The dimensional perspective of the "danger zone" in mandibular molars is that thin areas exist in the distal portion of the mesial root. ${ }^{32}$ These thin areas in the distal wall, which have been found to be sites of perforation during orthograde preparation, are compared with opposing thicker or "safety zone', areas in the mesial portion of the root. In maxillary molars because the distal canal wall thickness in coronal mesiobuccal root sections is thinner by $33 \%$, concern for distal root perforation in the mesiobuccal root should be considered. ${ }^{14,21}$

\section{Apical enlargement to reduce the microbial load}

To eliminate microbes from the root canal system, some authors have suggested that the size of apical preparation may be important in achieving that desired outcome. ${ }^{33-39}$ Weine defined the master apical file size as enlarging the apical portion of the root canal system three sizes larger than the first file that binds at working length. ${ }^{90}$ This was accomplished after coronal flaring of the root canal 
system. It is unclear, however, where this binding occurred within the canal. ${ }^{40-42} \mathrm{~A}$ thorough search of the literature failed to show what an optimal apical preparation diameter might be and it still remains a subject of uncertainty. ${ }^{43}$ Some authors have suggested creating a 'larger' apical preparation, followed by a 1-week dressing with calcium hydroxide. ${ }^{33,44,45}$ Other authors have suggested enlarging the apical size to a predetermined size beyond sizes 35 or $40,{ }^{36-38,45-50}$ while others have suggested that enlarging the canal three sizes larger than the first apical binding file would be adequate. ${ }^{39,51-53}$ It seems unclear where this "apical" binding is actually taking place since Wu et al. reported that the first file to bind in the apical root canal system did not necessarily reflect the true canal diameter at the proposed working length because the apical anatomy is often irregularly shaped and not a round configuration. ${ }^{40}$ Therefore, preparing the apical canal to only three sizes larger than the first binding file does not ensure removal of the inner layer of dentin from all apical canal walls or all infected necrotic pulp tissue. ${ }^{40}$ Some authors have suggested that taper is more important than final apical size. It was reported that a taper of 0.10 allows for minimum instrumentation of the apical portion of the canal. ${ }^{53}$ Rocas et al. reported that in terms of bacterial reduction, there was no significant difference between hand files with 0.02 taper, and nickel-titanium and rotary files with 0.04 taper NiTi instrumentation. ${ }^{54}$ However, they also reported that rotary instrumentation with 0.04 taper had better microbial reduction in the same quantitative analysis by real-time polymerase chain reaction. In that study, the canals were instrumented to a similar apical diameter. However, Siqueira et al. reported that canal preparation to an apical size of 30 with a 0.02 taper was significantly more effective than rotary NiTi GT files with a size 20 tip and a 0.12 taper in reducing intracanal bacteria. ${ }^{55}$ Thus, it can be concluded that both taper and diameter are equally important in chemo mechanical instrumentation of the root canal system in reducing the bioburden. To date, only a few studies have addressed the clinical outcome of various master apical file sizes (MAFS), and despite conflicting claims, the ideal MAFS remains undefined in 
any individual canal. ${ }^{34,37,39,44,53,57}$ In a systematic review, the authors reported that there was only one randomized controlled clinical trial (RCT) available to indicate that in patients with necrotic pulps undergoing root canal treatments, enlargement of the apical diameter resulted in a better healing outcome than smaller diameters. ${ }^{57}$

\section{Larger apical preparation to promote irrigant efficacy}

Numerous studies have shown that mechanical cleaning of the root canal system alone is ineffective in completely removing bacteria. ${ }^{37,38,49,51,56,58,59}$ By using a chemical antibacterial agent such as sodium hypochlorite $(\mathrm{NaOCl})$, ethylenediametetraacetic acid (EDTA), or chlorhexidine $(\mathrm{CHX})$ in conjunction with mechanical cleaning, there was a significant improvement in disinfection of the canal system. This is essential for the success of endodontic therapy. ${ }^{33,36}$ Due to the complexity of root canal anatomy, there is currently no known antibacterial agent or irrigation device that can completely kill microorganisms in the canal system; therefore, adequate enlargement of the canal system allows for irrigation to become a critical step in achieving a high success rate for endodontic treatment ${ }^{60,91}$

Brunson et al. studied the effect of apical preparation size and taper on irrigant volume delivered. ${ }^{61}$ The study included 40 human single rooted teeth, and was divided into two phases. In the first phase, all samples were prepared with 6\% taper and differing tip sizes, ranging from ISO sizes 30 to 45 . In the second phase, canals were prepared using the same tip size, but with different taper, ranging from $2 \%$ taper to $8 \%$ taper files. All samples were irrigated with a negative pressure microcannula with $\mathrm{NaOCl}$ at working length for 30 seconds. Irrigant was collected and the volume was measured. The results were a $44 \%$ increase in volume of irrigant delivered when increasing apical diameter from ISO size 35 to 40 . A change from ISO size 40 to 45 resulted in a $4 \%$ increase in volume. When comparing the taper size, a canal enlargement from 40.02 to 40.04 , had a $74 \%$ irrigant 
volume increase; 40.04 to 40.06 had a $5.4 \%$ irrigant volume increase; 40.06 to a 40.08 had $2.4 \%$

volume increase. This study concluded that apical preparation should be enlarged to an ISO size 35 to 40 with a $4 \%$ tapered file. Such sizes are well balanced between the volumes of the irrigant introduced to the canal, while maintaining the integrity of the root structure.

\section{$\underline{\text { 6. Residual dental thickness (RDT) }}$}

There has been an ongoing clinical dilemma between the importance of adequate apical enlargement for removing bacteria and necrotic tissue and the necessity of preserving the integrity of root structure. ${ }^{62}$ Many studies have recommended that the root canal space in the coronal segment should not exceed one third of the root diameter in all levels to preserve its mechanical integrity. ${ }^{63-65}$ It has also been recommended that a minimum of $1 \mathrm{~mm}$ circumference of remaining dentinal thickness should be maintained, as to not jeopardize root structure integrity. ${ }^{66,67}$ 


\section{Chapter 3}

\section{Materials and Methods}

The application and approval for the Institutional Review Board (IRB) was applied for and obtained at West Virginia University. The IRB protocol tracking number is 1411494231 . Forty extracted de-identified first and second human maxillary molars were obtained. The teeth were each marked with sample numbers for identification and preserved in normal saline solution (Figure 5). A dental hygiene student performed scaling and root planning to remove gross calculus and plaque from these teeth.

The cleaned teeth were secured with utility wax to the center of a digital sensor (Kodak RVG 6100; Carestream Health, Rochester, NY). Radiographic images were taken with the X-ray tube in a fixed position (Figure 6), and exposures were made in the bucco-lingual and mesio-distal planes of each tooth. The images were recorded in MiPACS imaging software (Medicor Imaging, Charlotte, NC, USA).

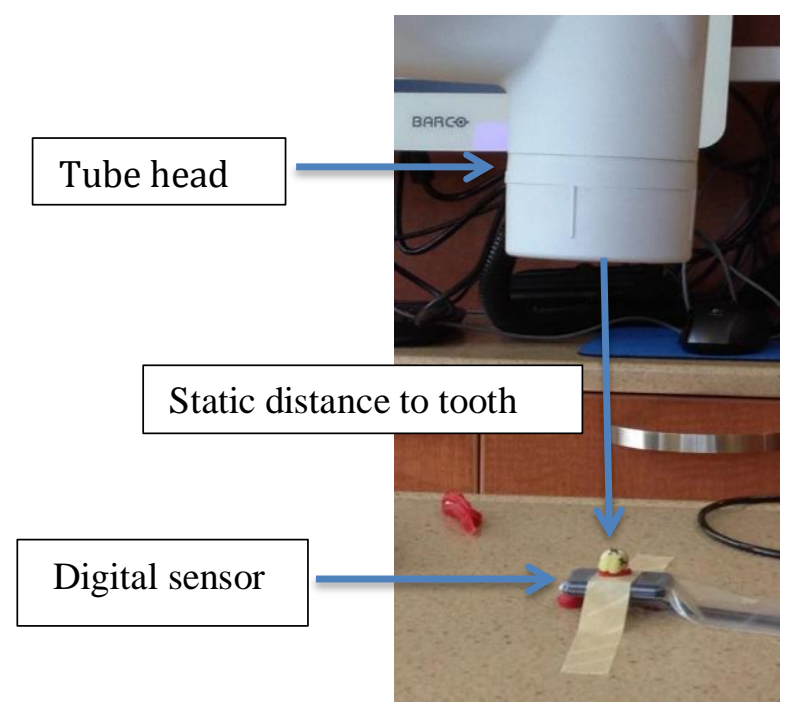

Figure 5. Radiograph for each tooth 
The radiographs were examined to ensure that all maxillary root canals were visible radiographically. At the completion of the assessment, 30 of the 40 molars were chosen for inclusion in the study. The mean curvature of the mesiobuccal roots was $20^{\circ}$ (Range: $10^{\circ}$ to $35^{\circ}$ ). The calculation of root curvature has been described by Schneider as a line drawn parallel to the long axis of the root canal and a second line drawn from the apical foramen to intersect with the first line at the outermost point of the canal. ${ }^{68}$ The teeth were randomly divided into 2 groups (Figure 7)

The specimens were mounted at the cemento-enamel junction (CEJ) in modified polypropylene 50-ml centrifuge tubes (Thermo Fisher Scientific, Waltham, MA) using a radiolucent methyl methacrylate acrylic resin (Varidur® Buehler LTD, Lake Bluff, IL) (Figure 8). Each tooth was embedded upright in one centrifuge tube. The facial and mesial surfaces of each tooth were marked for scanning purposes to ensure operator consistency (Figure 9).

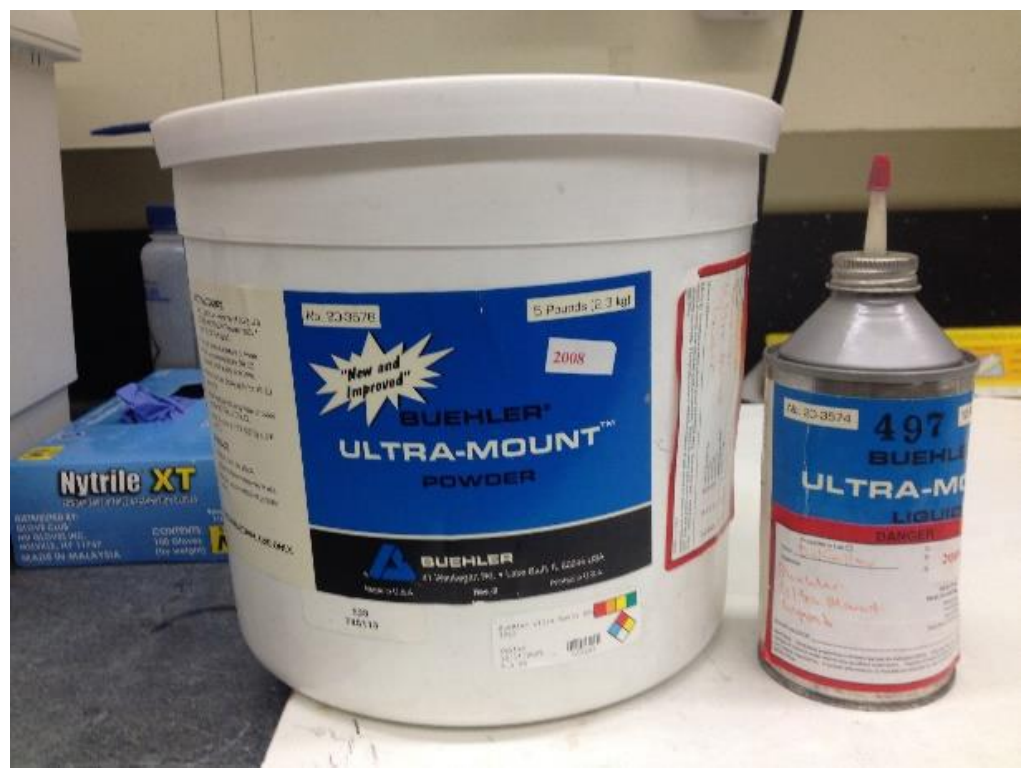

Figure 6. Radiolucent methyl methacrylate acrylic resin 

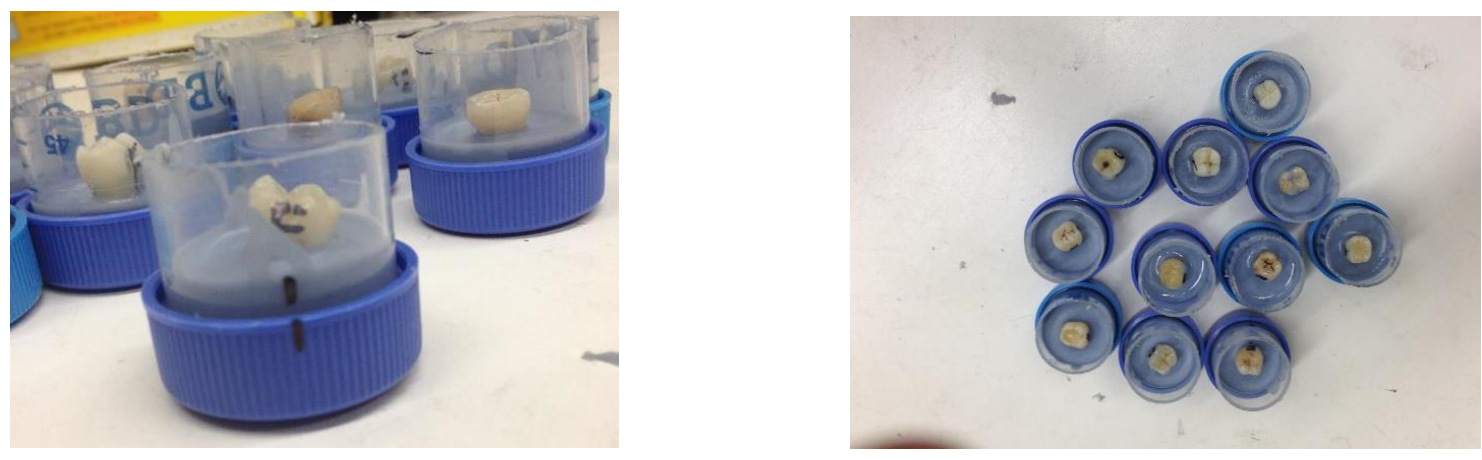

Figure 7. Tooth was mounted in the tube and buccal surface was marked

Scanning of the teeth was conducted at the National Institute of Standards and Technology (NIST) (Gaithersburg, Maryland). A microCT-40 (Scanco Medical, Switzerland) with an isotropic voxel size $(18 \mu \mathrm{m})$ was utilized to scan the specimens. The radiographic settings were $75 \mathrm{kVp}$ and $114 \mu \mathrm{A}$ (Figure 10). All specimens were covered with wet paper towel and sealed with paraffin wax to keep teeth moisturized during the experiment. The teeth were mounted in a centrifuge tube that was inserted into a sample holder for mCT measurement (Figure 11a). The sample holder was then placed on the specimen table inside the chamber of the microCT-40 to be scanned (Figure 11b).

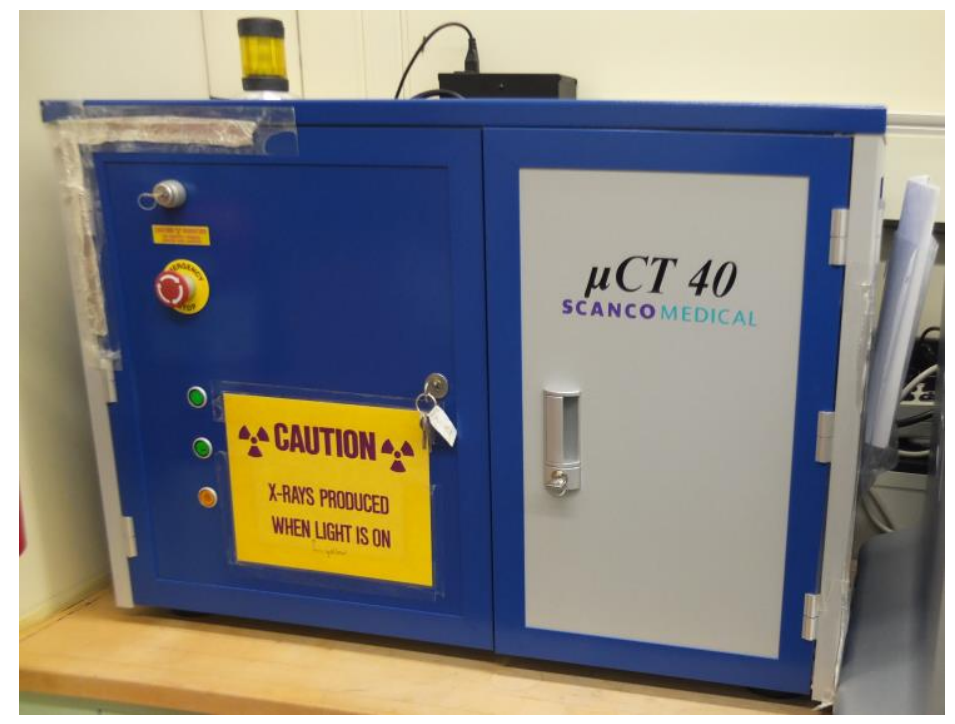

Figure 8. MicroCT-40 (Scanco Medical, Switzerland). 


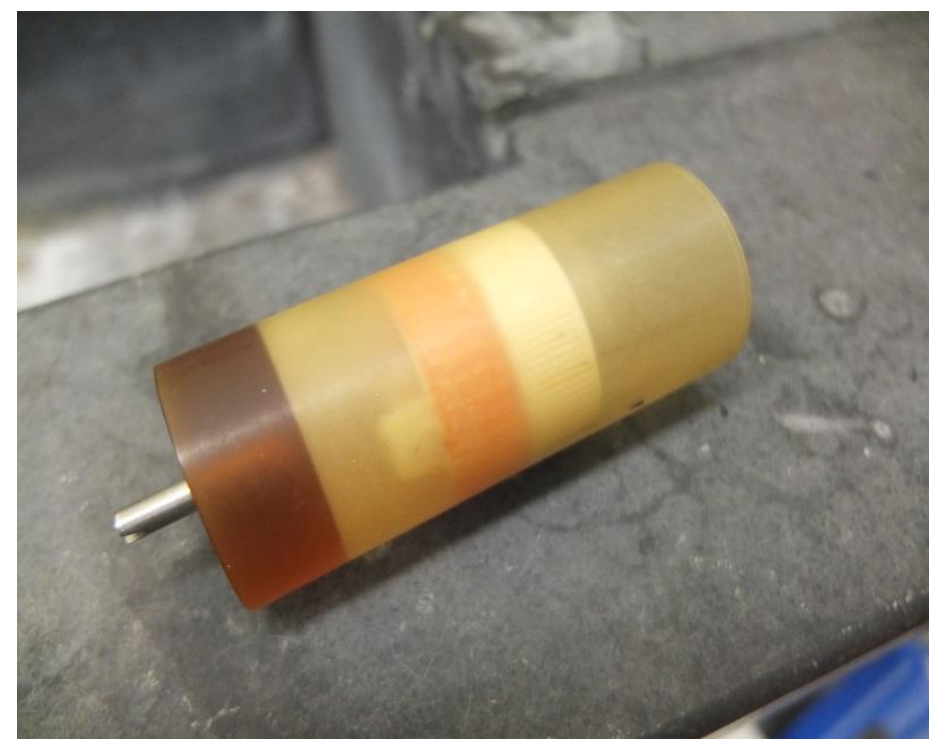

Figure 9a. Tooth mounted centrifuge tube was inserted into a sample holder for mCT measurement.

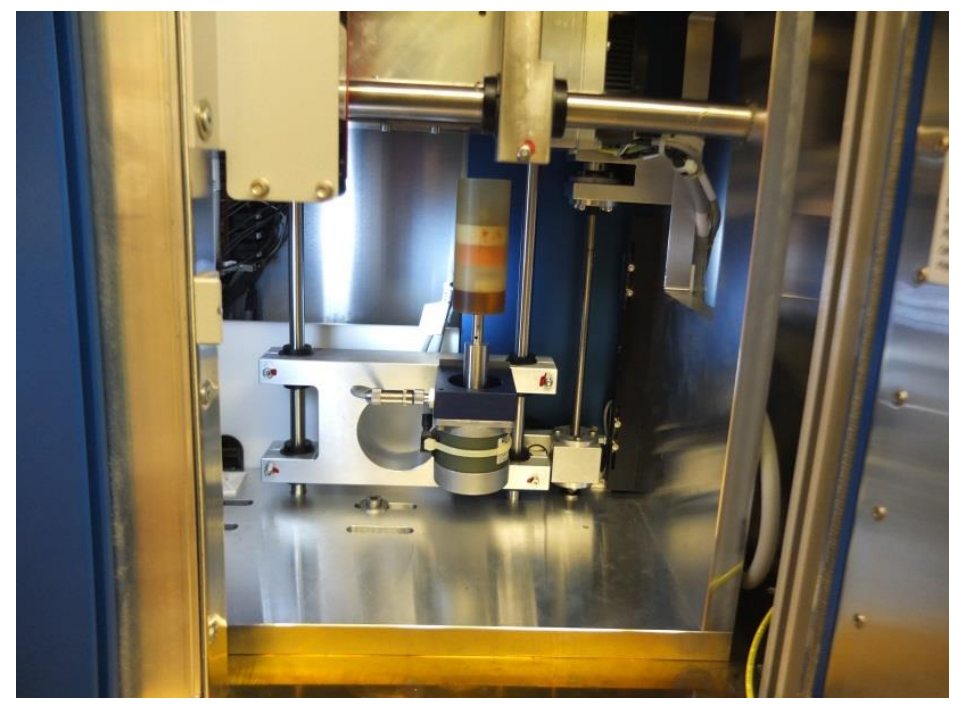

Figure 9b. The sample holder was placed on the Specimen table inside the chamber of the Micro CT40 .

Images from the microCT-40 were transferred to ImageJ ${ }^{\circledR}$ image analyzing software (NIH, Bethesda, MD) to assess initial dentin thickness of the dentinal wall of each canal of each mesial buccal root when measured $1 \mathrm{~mm}$ from the apex. A cross sectional image at $1 \mathrm{~mm}$ was used for measurement. 
The extent and direction of canal transportation was determined by measuring the shortest distance from the edge of the uninstrumented canal to the edge of the tooth in both a mesial and distal directions and then comparing this with the same measurements taken from the instrumented images. The following formula was used for the transportation calculation: (X1 - X2) - (Y1 - Y2). X1 represented the shortest distance from the outside of the curved root to the periphery of the uninstrumented canal, Y1 represented the shortest distance from the inside of the curved root to the periphery of the uninstrumented canal, X 2 represented the shortest distance from the outside of the curved root to the periphery of the instrumented canal, and Y2 represented the shortest distance from the inside of the curved root to the periphery of the instrumented canal (Figure 12). A result of 0 from the canal transportation formula indicates no canal transportation..$^{10}$ To get the mean transportation scores absolute values were used.

The mean centering ratio is a measure of the ability of the instrument to stay centered in the canal. This ratio was calculated for each section using the following ratio: (X1 - X2) to (Y1 - Y2). The numerator for the centering ratio formula was the smaller of the two numbers (X 1 - X2) or (Y1 - Y2), if these numbers were unequal (Figure 12). Using this formula, a result of 1 for the centering ratio would indicate perfect centering. ${ }^{10}$ Absolute values were also used to get the centering ratio values. 


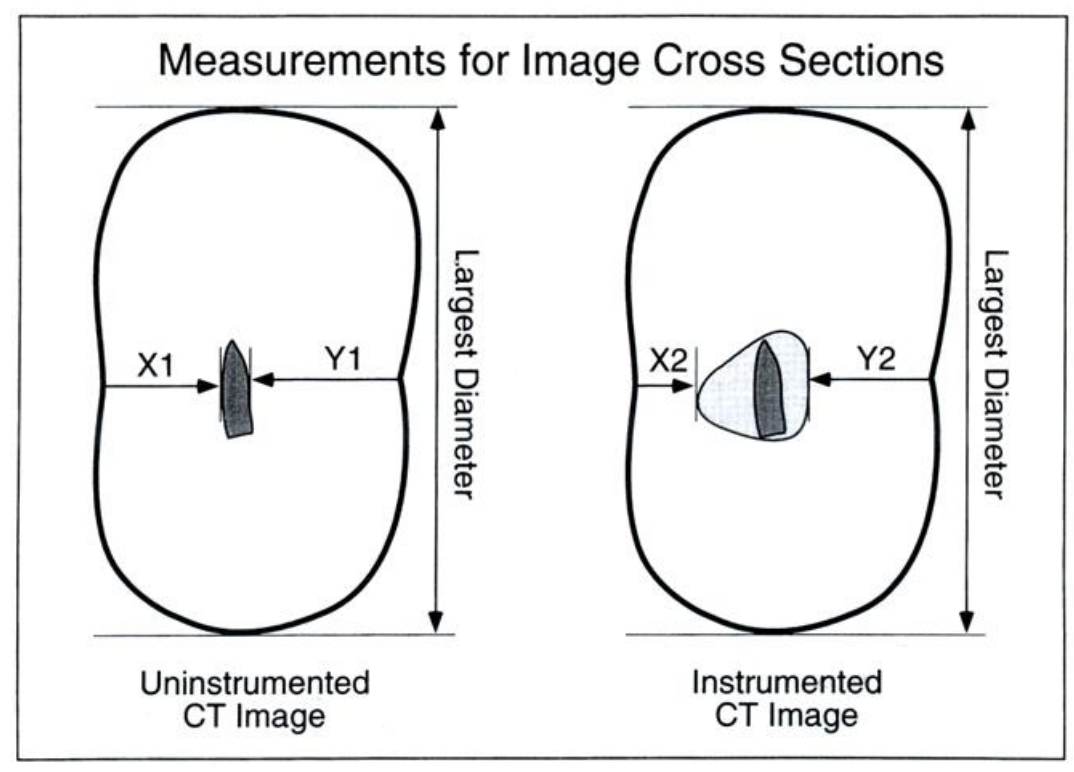

Figure 10. Representative drawing of tooth sections showing how transportation, centering ratios, and largest diameter of the tooth were derived. Uninstrumented image (left): original canal space represented by dark shaded area. Instrumented image (right): light shaded area represents canal shape after instrumentation. Largest diameters of tooth measurements were used to compare the scans to actual teeth sections.

One operator performed the mechanical shaping of the canals to minimize operator variation. The teeth initially were accessed with a 330 carbide bur (Brasseler USA, Savannah, GA, USA) in high speed handpiece with water coolant. Once in the chamber, Endo-Z bur (Dentsply, York, PA, USA) was used to enlarge the access outline and to facilitate locating the MB and DB orifices. Canals were initially negotiated with a size $10 \mathrm{~K}$ file (Flexofile ${ }^{\circ}$, Dentsply, York, PA, USA). The working length (WL) was established $1 \mathrm{~mm}$ short of the radiographic apex. A glide path was established with size 15 K file, (Flexofile ${ }^{\circ}$, Dentsply, York, PA, USA) and canals were sequentially instrumented to length with nickel titanium rotary files according to the group they were assigned. Also, speed and torque were set according to the manufacturer's instructions for that specific file and were then set on the rotary motor (Endo-MateDT, NSK Dental LLC, Hoffman Estates, IL, USA). The nickel titanium rotary files were also used in a fashion that followed the manufacturer's recommendations, utilizing an in and out motion. Canals were rinsed with $5 \mathrm{ml}$ of $2.5 \% \mathrm{NaOCl}$ between each file change using a 30 
gauge side vented needle (Prorinse®, Dentsply, York, PA, USA). Needles were inserted as deep as possible without binding in the canal. Once the canal was instrumented to length, a final rinse of sterile water was used and the canal was dried with sterile paper points.

The teeth were scanned after canal preparation in a manner identical to the pre-instrumentation scan. Each specimen's images were then transferred to ImageJ® to measure RDT in a manner identical to the pre-instrumentation measurement (Figure 13). All specimens were covered with wet paper towel and sealed with paraffin wax to keep teeth moisturized during the experiment.

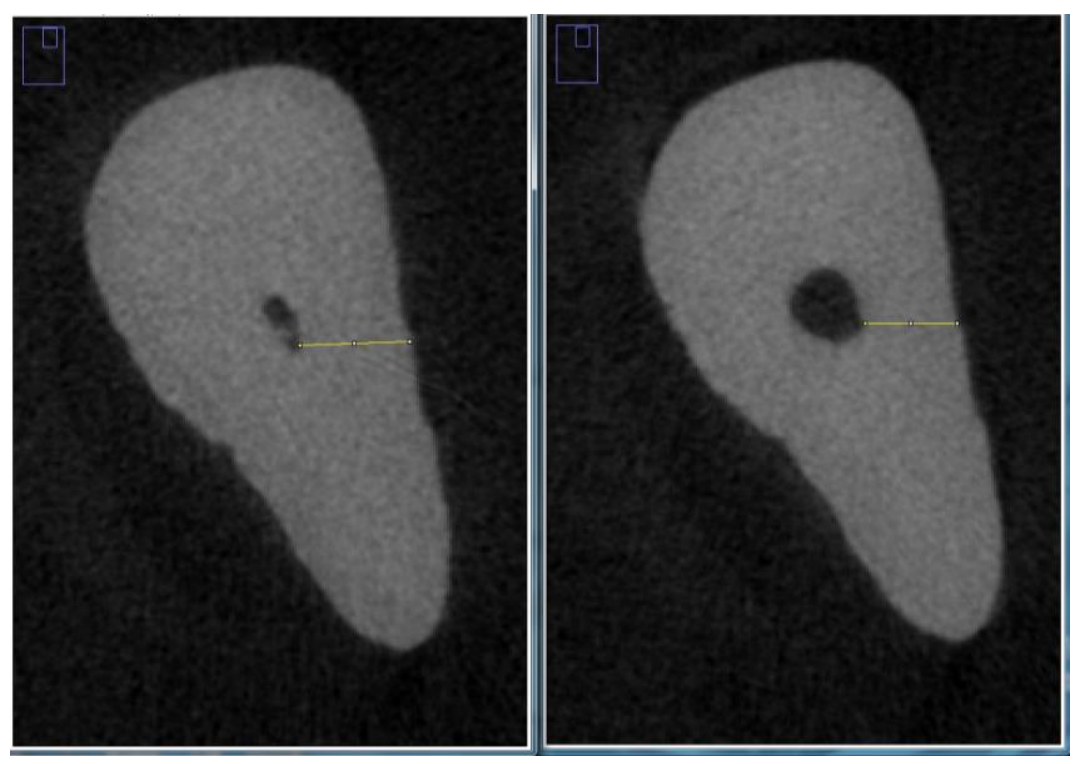

Figure 11. Micro CT; Before preparation showing X1 on the left and after preparation showing X2 on the right. 


\section{Statistical Analysis}

\section{Statistical Methods}

All available observations ( $\mathrm{N}=30)$ were used in analyses. Distribution and sample size considerations were explored to determine the correct analysis plan for each research measure. Wilcoxon Rank Sum tests were found to be appropriate for comparisons of both transportation measures and centering ratios. All statistical tests were performed at the $95 \%$ significance level. Data management, diagnostics, and analyses were carried out solely in SAS 9.3 (SAS Inc., Cary, NC). 


\section{Chapter 4}

\section{Results}

\section{$\underline{\text { Transportation }}$}

Fifteen teeth were each divided into respective EdgeEvolve and Trushape groups and transportation measure differences were analyzed using a Wilcoxon Rank Sum test (respective distributions of transportation measures can be found in Figure 14). The teeth in the TruShape group $(\mu=0.00253, \mathrm{SD}=0.00177)$ had statistically significantly smaller transportation measures than those in the Edge Evolve group $(\mathrm{M}=0.00453, \mathrm{SD}=0.00283)$ at the $95 \%$ significance level $(\mathrm{W}=287.0, \mathrm{p}=$ $0.023)$.

\section{Centering Ratio}

Fifteen teeth were each divided into respective EdgeEvolve and Trushape groups and centering ratio differences were analyzed using a Wilcoxon Rank Sum test (respective distributions of centering ratios can be found in figure 16). The teeth in the TruShape group $(\mu=0.323, \mathrm{SD}=0.287)$ did not differ in a statistically significant manner with measures from those in the Edge Evolve group $(\mathrm{M}=$ $0.379, \mathrm{SD}=0.258)$ at the $95 \%$ significance level $(\mathrm{W}=256.0, \mathrm{p}=0.337)$.

During instrumentation, all 30 specimens were found to be apically patent with size $10 \mathrm{~K}$ files, and patency was maintained during the instrumentation procedures. No separation of any NTR instruments occurred during the mechanical preparation phase of the experiment. Based upon evaluation of radiographs, no visible perforations, ledges or apical strippings were detected. 


\begin{tabular}{|c|c|c|c|}
\hline & \# of teeth & Mean \pm St. Dev. & Median \\
\hline \multicolumn{4}{|l|}{ Transportation } \\
\hline EdgeEvolve $^{\mathrm{TM}}$ & 15 & $0.0045 \pm 0.0028$ & 0.005 \\
\hline TruShape ${ }^{\circledR}$ & 15 & $0.0025 \pm 0.0018$ & 0.002 \\
\hline \multicolumn{4}{|l|}{ Centering Ratios } \\
\hline Edge Evolve ${ }^{\mathrm{TM}}$ & 15 & $0.379 \pm 0.258$ & 0.330 \\
\hline True Shape ${ }^{\circledR}$ & 15 & $0.323 \pm 0.287$ & 0.250 \\
\hline
\end{tabular}

Table 1. Shaping outcomes of canal transportation and centic ability of MB canals with EdgeEvolve ${ }^{\mathrm{TM}}$ and TruShape ${ }^{\circledR}$.

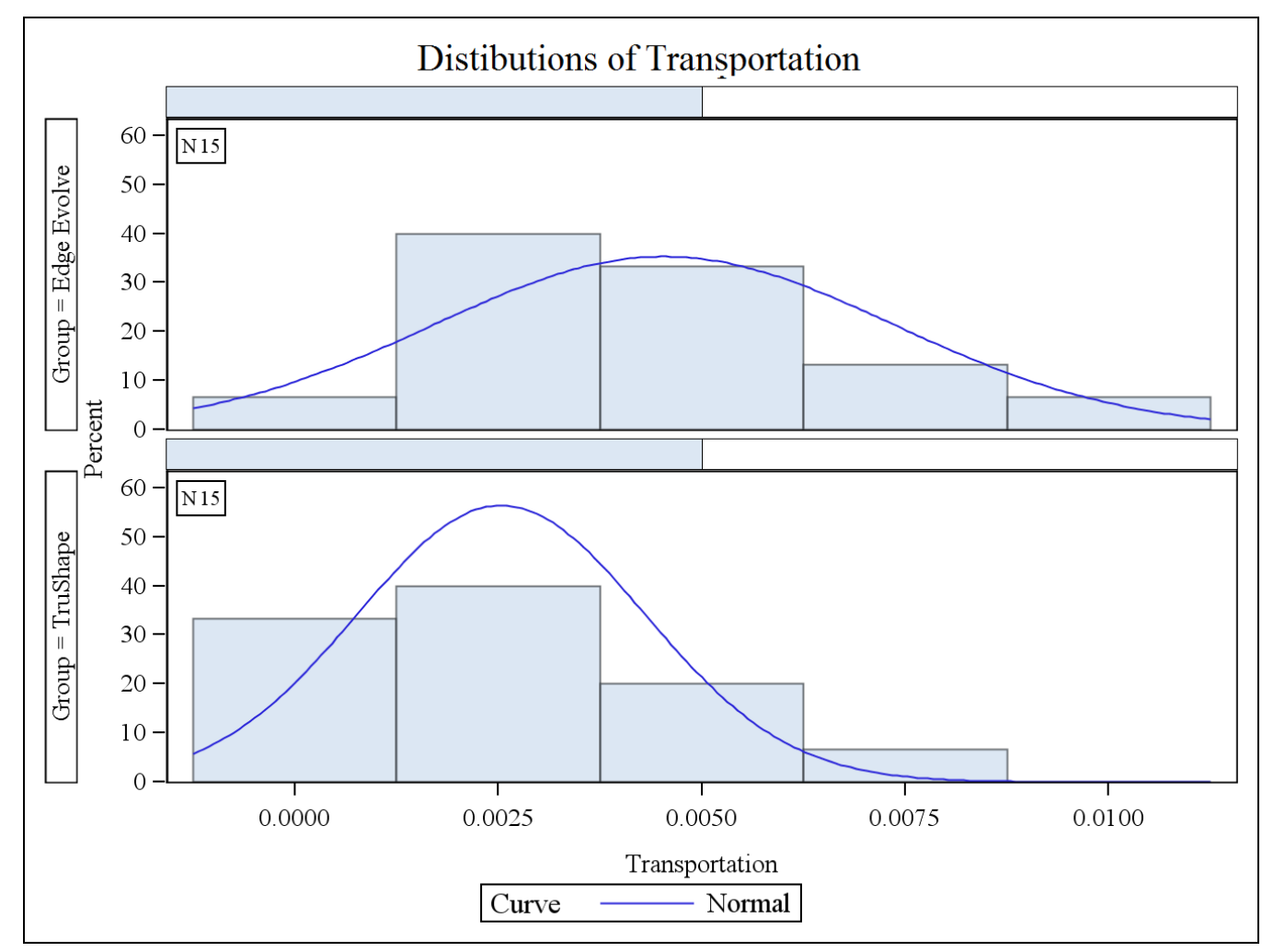

Figure 12. Diagrammatic illustration of the respective distributions of transportation scores for EdgeEvolve ${ }^{\mathrm{TM}}$ and TruShape $\AA$. 


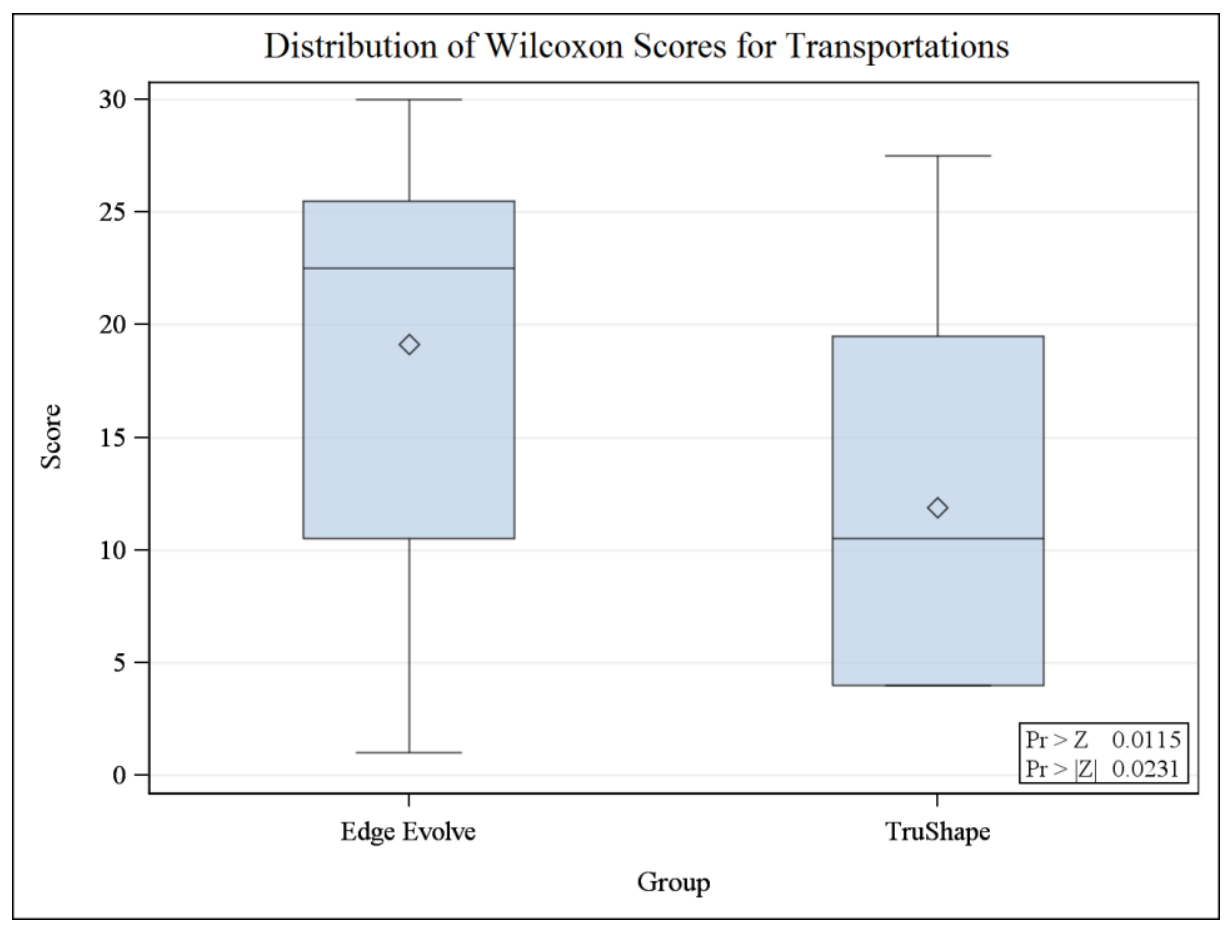

Figure 13. Diagrammatic representation of the respective distributions of the Wilcoxon scores for transportation. The diamond is the mean score $\&$ the straight line is the median score.

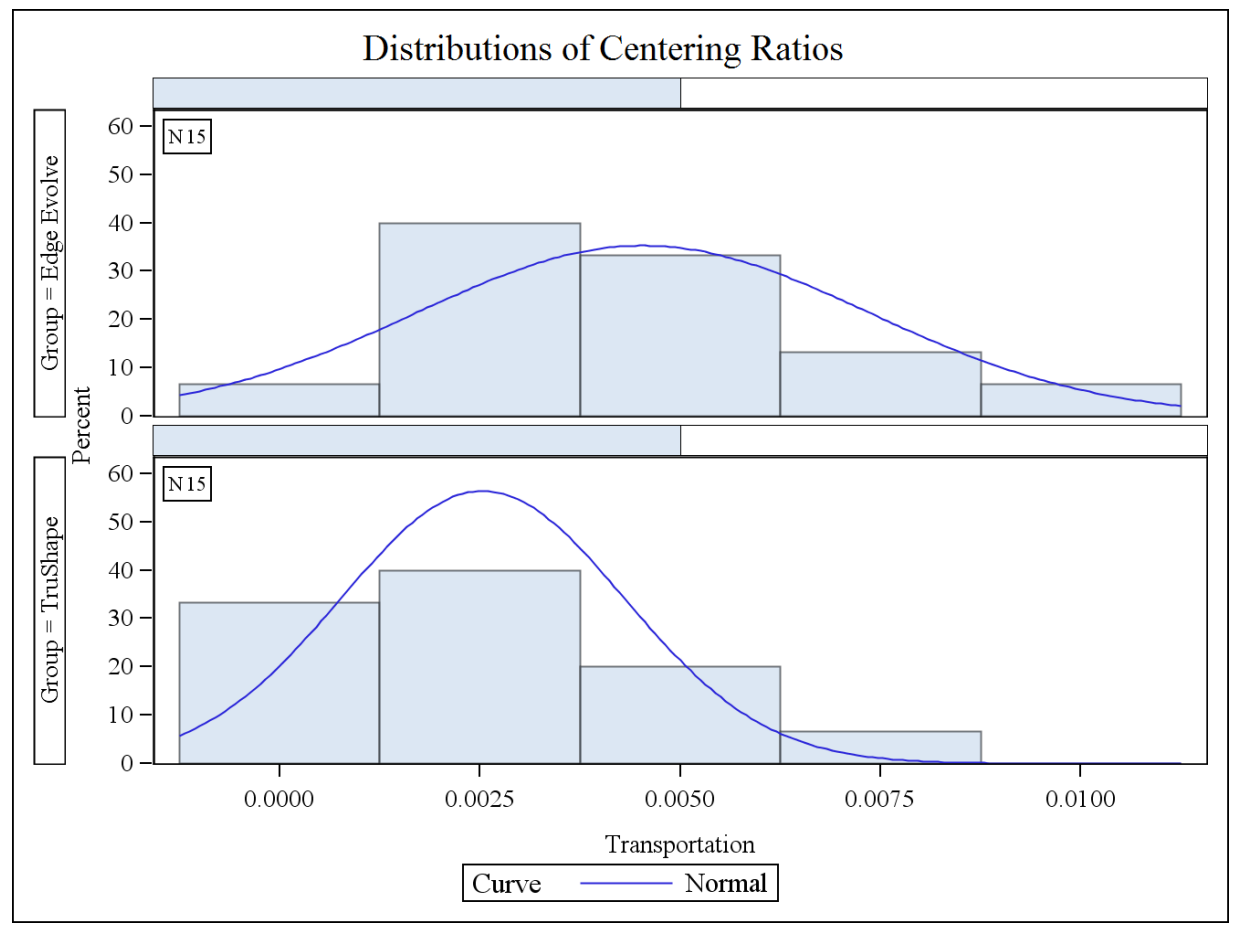

Figure 14. Diagrammatic illustration of the respective distributions of centering ratio scores for EdgeEvolve ${ }^{\mathrm{TM}}$ and TruShape ${ }^{\circledR}$. 


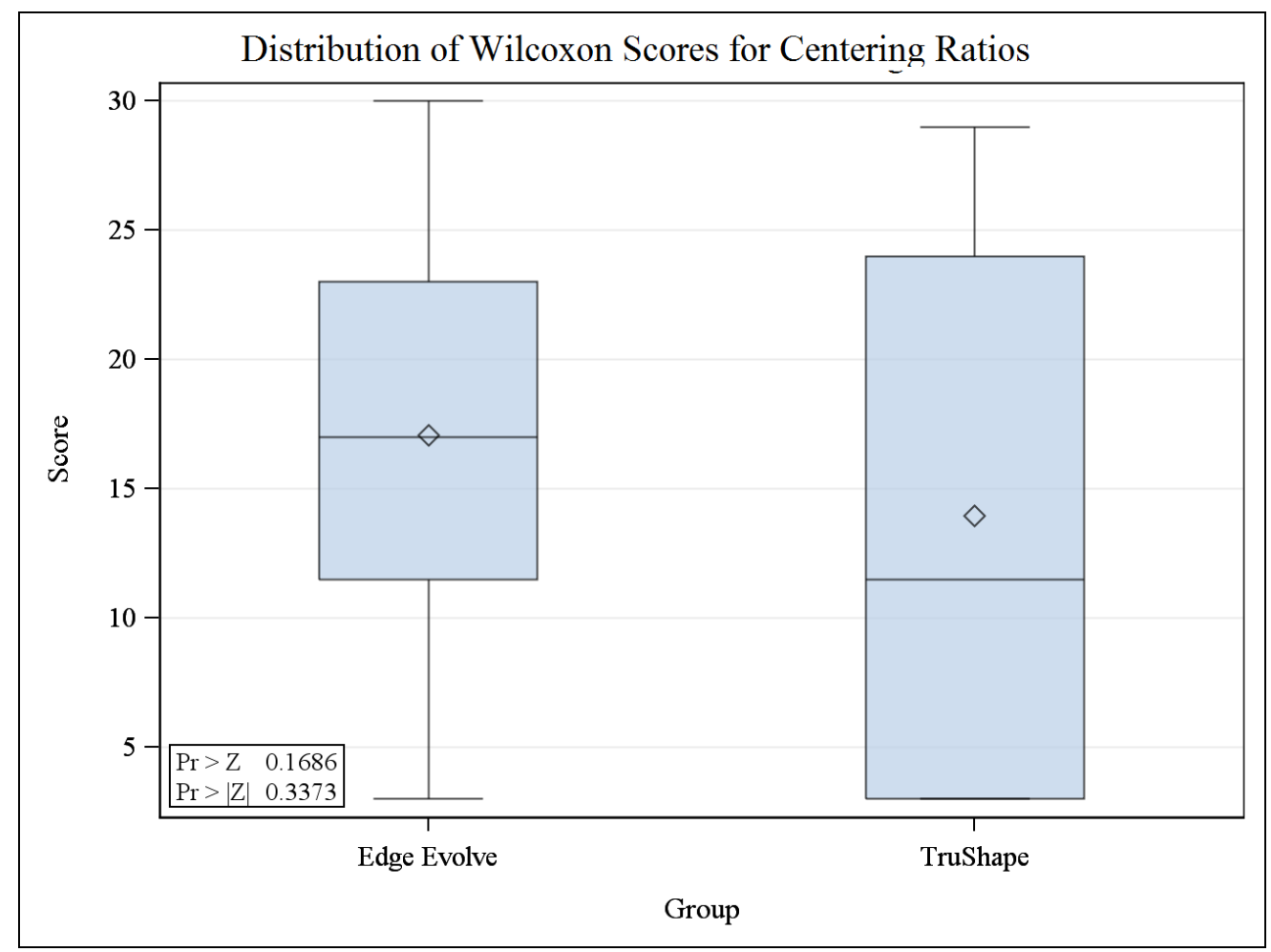

Figure 15. Diagrammatic representation of the distributions of the Wilcoxon scores for centering ratios. The diamond is the mean score $\&$ the straight line is the median score. 


\section{TRUShape® PREPARATION}

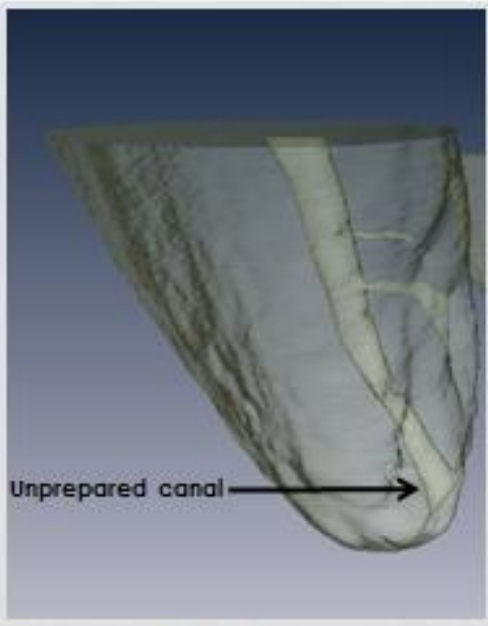

Before

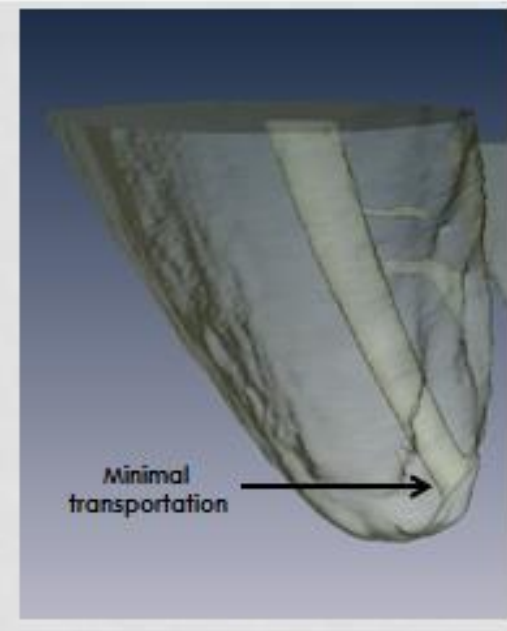

After

Figure 16. An illustration of TRUShape ${ }^{\circledR}$ preparation with minimal transportation

\section{EdgeEvolve $^{\text {TM }}$ PREPARATION}

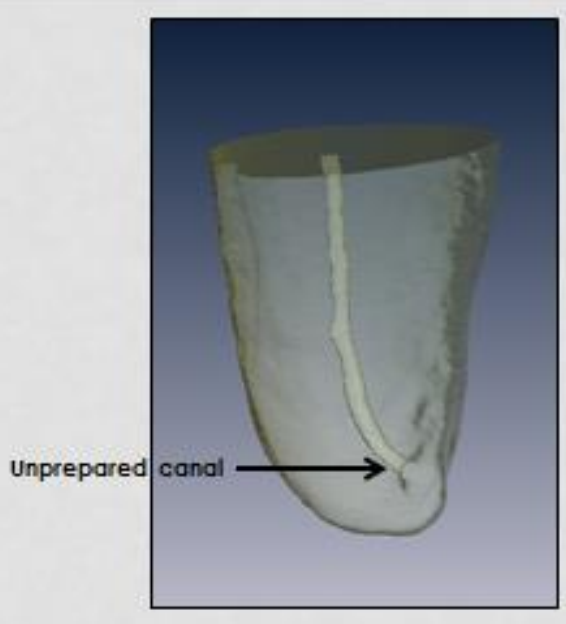

Before

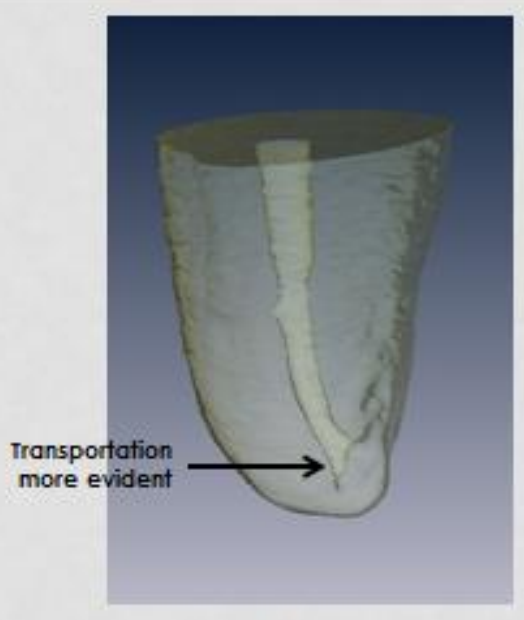

After

Figure 17. An illustration of EdgeEvolve ${ }^{\mathrm{TM}}$ preparation showing more evident transportation 


\section{Discussion}

This study was designed to determine the canal transportation and centric ability of TRUShape ${ }^{\circledR}$ and EdgeEvolve ${ }^{\mathrm{TM}}$ files and whether or not there is a statistical difference of those parameters between the two file systems. Due to distributional and sample size concerns, nonparametric methods were used in analyses, and each individual measure per observation, whether it be centering ratio or transportation, was looked at in a "rank" sense within the context of the other measures. Transportation was shown to be lower in the TRUShape ${ }^{\circledR}$ group, however, there was no statistical significant difference in centering ratios. This means that even while the transportation values in EdgeEvolve $\mathrm{TM}^{\mathrm{TM}}$ group may have been higher, the ratio of the movement either to the right or to the left was almost the same between the groups. Essentially, if EdgeEvolve ${ }^{\mathrm{TM}}$ recorded a certain centering ratio for one tooth, then TRUShape ${ }^{\circledR}$ would record a similar centering ratio, albeit with a lower transportation value in either horizontal direction. In fact, while EdgeEvolve ${ }^{\mathrm{TM}}$ removed more of the tooth than TRUShape ${ }^{\circledR}$ it stayed slightly closer to the center of the tooth, however, this is not a statistically significant result. Furthermore, Even though there is a statistical significant difference in the transportation scores between the two file systems it is in microns and it is not of any clinical significance.

Mesiobuccal root canals of extracted human maxillary molars were used in the present study because they usually present an accentuated curvature, mesiodistal flattening and are extremely narrow. These characteristics are additional shortcomings in root canal therapy during chemomechanical instrumentation and make cleaning and shaping of these canals more difficult, mainly in isthmus areas where there is more chance of iatrogenic mishaps.

A number of cleaning and shaping principles and practices have been previously suggested and should be followed to achieve optimum results in canal preparation. These principles include; first, 
development of a continuously tapering funnel from the coronal access cavity to the root apex; second, following the original canal shape; and third, maintaining the apical foramen in its original spatial relationship both to the periapical tissues and to the root surface. ${ }^{3}$ However, it is more difficult to adhere to these principals in curved canals because current instrumentation techniques are more likely to divert the canal away from its original axis. This increases the chances of procedural errors, which includes canal transportation, apical zipping, ledging and strip perforations. ${ }^{69} 7071$

The anatomy of the maxillary first and second molars in this study compared to the different canal configurations in micro CT study by Somma. ${ }^{23}$

Apical transportation may be managed by altering your treatment strategy according to the type of transportation. In canals exhibiting type I transportation, if sufficient residual dentin is maintained and the preparation shape above the foramen can be corrected then the canal can be cleaned and obturated. Type II cases are managed by placing a barrier to control bleeding and provide a backstop to pack against during subsequent obturation procedures. In type III situations, a barrier technique is usually not feasible; it requires obturation as best as possible followed by corrective surgery. ${ }^{92}$

Studies have indicated that differences in canal anatomy - straight or curved/ flat or oval/ narrow or wide- when comparing roots would play a significant role for shaping outcomes. ${ }^{13}$ More ribbonshaped or flat canals such as mesiobuccal canals would have more unprepared canal areas and greater canal transportation than found in larger palatal canals. Different preparation techniques and instruments have been developed and modified to overcome the challenges that curved canals present. Nickel titanium (NiTi) files have been shown to significantly reduce procedural errors when compared to hand instruments. ${ }^{29} 727374$ 
Most of the NiTi rotary instruments presently operate in continuous rotary motion. However, several studies have suggested uisng a reciprocating rotary motion as an alternative to continuous rotary motion in order to increase fatigue resistance and decrease procedural errors, while still increasing efficiency and decreasing procedural times. ${ }^{75} 7677$ The reciprocating rotary movement is based on the balanced force technique, which was designed to maintain the curvature without distorting the shape of the root canal. 7879

More studies are needed to compare those file systems in regard to other parameters such as amount of remaining unprepared canal walls, amount of remaining bacteria and amount of unnecessary dentin removal.

A study by Peters and others has shown canal transportation to be found most frequently in the apical region. The mean scores in their study varied from 1.8 to $50 \mu \mathrm{m}$, and that apical transportation occurs mainly in an outward direction in relation to the greater curvature regardless of the instrumentation technique used. ${ }^{29}$

Another study by Peters and others compared TRUShape ${ }^{\circledR}$ files with an established fixed taper instrument, Vortex ${ }^{\circledR}$ files, in mesial roots of mandibular molars. ${ }^{30}$ According to this study transportation scores were averaged over root canal thirds and ranged from $53 \pm 19 \mu \mathrm{m}$ to $179 \pm 65 \mu \mathrm{m}$. Absolute canal transportation was significantly different $(\mathrm{P}<0.5)$ at each canal third. Moreover, TRUShape ${ }^{\circledR}$ removed less bulk dentin and left more dentin wall. This difference was significant and amounts to about $36 \%$ and $26 \%$ less dentin removed when preparing to apical sizes \#20 and \#30, respectively.

The following are studies that do not directly relate to canal transportation but they are included to show other parameters that were evaluated for the novel file TRUShape®. 
The amount of unprepared canal surface has been the focus of many studies in the mesial root canals of mandibular molars and has been found to vary greatly, from about $16 \%$ to $48 \% .^{80-85}$ The same study by Peters and others comparing TRUShape ${ }^{\circledR}$ and Vortex ${ }^{\circledR}$ found that shaping to a size $\# 20$ with either instrument is sufficient to attain a high proportion of instrumented surface of the canal wall. ${ }^{30}$ However, at size \#30, $85 \%$ or more of the mesial canal surface in mandibular molars was instrumented by both files.

A study by Brotoluzzi and others measured the efficacy of TRUShape ${ }^{\circledR}$ in eliminating canal wall bacteria from oval shaped root canals in maxillary single rooted premolars when compared to Twisted ${ }^{\circledR}$ Files. ${ }^{86}$ This study found that TRUShape ${ }^{\circledR}$ files removed significantly more canal wall bacteria than Twisted® Files when used without an antibacterial irrigant, and that an antibacterial irrigant is required to decontaminate dentinal tubules.

A study by Zuolo and others compared the efficacy of TRUShape ${ }^{\circledR}$ and Reciproc $®$ file systems in the removal of root canal filling material using micro CT ${ }^{87}$ This study found that there was no difference regarding the percentage of remaining filling material when comparing both file systems; however, Reciproc ${ }^{\circledR}$ was faster than TRUShape ${ }^{\circledR}$.

A study by Vasconcelos and others evaluated the effect of two different temperatures $\left(20^{\circ} \mathrm{C}\right.$ and $37^{\circ} \mathrm{C}$ ) on the cyclic fatigue life of rotary instruments and correlated the results with martensitic transformation temperatures. ${ }^{88}$ This study found that for the tested size $\# 25$ at $20^{\circ} \mathrm{C}$, Hyflex $\mathrm{CM}{ }^{\circledR}$ showed the highest resistance to fracture; no significant difference was found between TRUShape ${ }^{\circledR}$ and Vortex Blue ${ }^{\circledR}$, Pro-Taper Universal ${ }^{\circledR}$ showed the lowest resistance to fracture. At $37^{\circ} \mathrm{C}$, resistance to fatigue fracture was significantly reduced up to $85 \%$, for the tested instruments $(\mathrm{P}<.001)$; at that temperature, Hyflex $\mathrm{CM} \circledast$ and Vortex Blue ${ }^{\circledR}$ had similar and higher fatigue resistance compared with TRUShape ${ }^{\circledR}$ and ProTaper Universal®. 
According to the EdgeEndo ${ }^{\circledR}$ website an internal study was conducted on cyclic fatigue rates.

Average time to failure in seconds was tested comparing EdgeEvolve ${ }^{\mathrm{TM}}$, Vortex Blue ${ }^{\circledR}$, Sybron K3XF®, Sybron K-3®, GT Series X®, Protaper®, Sequence® files. The results are shown in (Figure 20). This data showed that EdgeEvolve ${ }^{\mathrm{TM}}$ files have a time to failure that is more than double the time to failure for Vortex Blue ${ }^{\circledR}$ files, which is more than all the other files tested. No other studies performed on EdgeEvolve ${ }^{\mathrm{TM}}$ were found during my literature search.

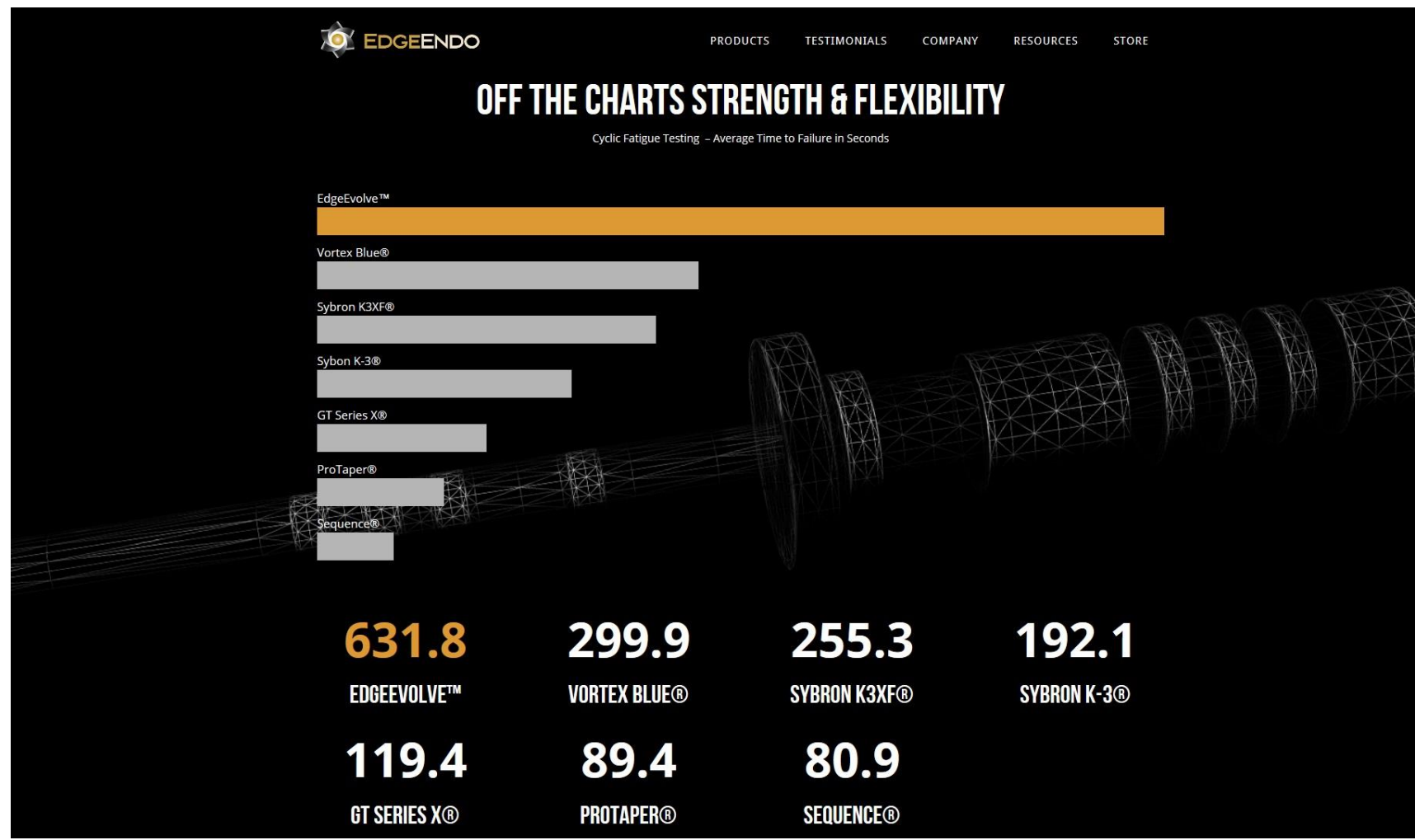

Figure 18. Cyclic fatigue rates for EdgeEvolve ${ }^{\mathrm{TM}}$, Vortex Blue ${ }^{\circledR}$, Sybron K3X®F, Sybron K-3®, GT Series X®, ProTaper ${ }^{\circledR}$, and Sequence ${ }^{\circledR}$ Files. 


\section{Chapter 5}

\section{Conclusion}

The amount of remaining dentin after shaping depends on canal transportation, and, in return, this number depends on canal curvature. Therefore, it is difficult to compare the present results with data from other studies; however, between the two instruments tested under present conditions, TRUShape ${ }^{\circledR}$, resulted in less canal transportation and more remaining dentin in the canal walls. It continues to be a matter of debate if the amount of preserved structure will translate into enhanced clinical outcomes. 


\section{Work Cited}

1. McRay B, Cox T, Cohenca N, Johnson J, Paranjpe A. A micro-computed tomography-based comparison of the canal transportation and centering ability of ProTaper universal rotary and WaveOne reciprocating files. Quintessence Int. 2014;45(2):101-108.

2. de Leon Del Bello,Teresa Ponce, Wang N, Roane JB. Crown-down tip design and shaping. $J$ Endod. 2003;29(8):513-518.

3. Schilder H. Cleaning and shaping the root canal. Dent Clin North Am. 1974;18(2):269-296.

4. Hartmann MSM, Barletta FB, Camargo Fontanella VR, Vanni JR. Canal transportation after root canal instrumentation: A comparative study with computed tomography. J Endod. 2007;33(8):962965.

5. Rhodes JS, Ford TRP, Lynch JA, Liepins PJ, Curtis RV. A comparison of two nickel-titanium instrumentation techniques in teeth using microcomputed tomography. Int Endod J. 2000;33(3):279285.

6. Bergmans L, Van Cleynenbreugel J, Wevers M, Lambrechts P. A methodology for quantitative evaluation of root canal instrumentation using microcomputed tomography. Int Endod J. 2001;34(5):390-398.

7. Hübscher W, Barbakow F, Peters OA. Root-canal preparation with FlexMaster: Canal shapes analysed by micro-computed tomography. Int Endod J. 2003;36(11):740-747.

8. Bernardes RA, Rocha EA, Duarte MA, et al. Root canal area increase promoted by the EndoSequence and ProTaper systems: Comparison by computed tomography. $J$ Endod. 2010;36(7):1179-1182.

9. Yamamura B, Cox TC, Heddaya B, Flake NM, Johnson JD, Paranjpe A. Comparing canal transportation and centering ability of endosequence and vortex rotary files by using micro-computed tomography. J Endod. 2012;38(8):1121-1125. 
10. Gambill JM, Alder M, del Rio CE. Comparison of nickel-titanium and stainless steel hand-file instrumentation using computed tomography. J Endod. 1996;22(7):369-375.

11. Nielsen RB, Alyassin AM, Peters DD, Carnes DL, Lancaster J. Microcomputed tomography: An advanced system for detailed endodontic research. J Endod. 1995;21(11):561-568.

12. Versiani MA, Pascon EA, de Sousa CJ, Borges MA, Sousa-Neto MD. Influence of shaft design on the shaping ability of 3 nickel-titanium rotary systems by means of spiral computerized tomography. Oral Surg Oral Med Oral Pathol Oral Radiol Endod. 2008;105(6):807-813.

13. Peters OA, Peters CI, Schönenberger K, Barbakow F. ProTaper rotary root canal preparation: Effects of canal anatomy on final shape analysed by micro CT. Int Endod J. 2003;36(2):86-92.

14. Zhao D, Shen Y, Peng B, Haapasalo M. Micro-computed tomography evaluation of the preparation of mesiobuccal root canals in maxillary first molars with hyflex CM, twisted files, and $\mathrm{K} 3$ instruments. J Endod. 2013;39(3):385-388.

15. Verma P, Love RM. A micro CT study of the mesiobuccal root canal morphology of the maxillary first molar tooth. Int Endod J. 2011;44(3):210-217.

16. Cleghorn BM, Christie WH, Dong CCS. Root and root canal morphology of the human permanent maxillary first molar: A literature review. J Endod. 2006;32(9):813-821.

17. KUTTLER Y. Microscopic investigation of root apexes. J Am Dent Assoc. 1955;50(5):544-552.

18. GREEN D. Stereomicroscopic study of 700 root apices of maxillary and mandibular posterior teeth. Oral Surg Oral Med Oral Pathol. 1960;13:728-733.

19. Palmer MJ, Weine FS, Healey HJ. Position of the apical foramen in relation to endodontic therapy. J Can Dent Assoc (Tor). 1971;37(8):305-308.

20. Marroquín BB, El-Sayed MAA, Willershausen-Zönnchen B. Morphology of the physiological foramen: I. maxillary and mandibular molars. J Endod. 2004;30(5):321-328. 
21. Degerness RA, Bowles WR. Dimension, anatomy and morphology of the mesiobuccal root canal system in maxillary molars. $J$ Endod. 2010;36(6):985-989.

22. Neaverth EJ, Kotler LM, Kaltenbach RF. Clinical investigation (in vivo) of endodontically treated maxillary first molars. J Endod. 1987;13(10):506-512.

23. Somma F, Leoni D, Plotino G, Grande N, Plasschaert A. Root canal morphology of the mesiobuccal root of maxillary first molars: A micro-computed tomographic analysis. Int Endod J. 2009;42(2):165-174.

24. Baratto Filho F, Zaitter S, Haragushiku GA, de Campos EA, Abuabara A, Correr GM. Analysis of the internal anatomy of maxillary first molars by using different methods. $J$ Endod. 2009;35(3):337342.

25. Imura N, Otani SM, R.C. Fagundes MI. PR 7 double canals in mesiobuccal roots of maxillary molars. J Endod. 1997;23(4):268-268.

26. Degerness R, Bowles W. Anatomic determination of the mesiobuccal root resection level in maxillary molars. J Endod. 2008;34(10):1182-1186.

27. Hsu YY, Kim S. The resected root surface. the issue of canal isthmuses. Dent Clin North Am. 1997;41(3):529-540.

28. Norman Weller R, Niemczyk SP, Kim S. Incidence and position of the canal isthmus. part 1. mesiobuccal root of the maxillary first molar. J Endod. 1995;21(7):380-383.

29. Peters OA, Laib A, Göhring TN, Barbakow F. Changes in root canal geometry after preparation assessed by high-resolution computed tomography. J Endod. 2001;27(1):1-6. doi: 10.1097/00004770200101000-00001.

30. Peters OA, Arias A, Paque F. A micro-computed tomographic assessment of root canal preparation with a novel instrument, TRUShape, in mesial roots of mandibular molars. $J$ Endod. 2015;41(9):1545-1550. 
31. Abou-Rass M, Jann JM, Jobe D, Tsutsui F. Preparation of space for posting: Effect on thickness of canal walls and incidence of perforation in molars. J Am Dent Assoc. 1982;104(6):834-837.

32. Orstavik D, Kerekes K, Molven O. Effects of extensive apical reaming and calcium hydroxide dressing on bacterial infection during treatment of apical periodontitis: A pilot study. Int Endod $J$. 1991;24(1):1-7.

33. Parris J, Wilcox L, Walton R. Effectiveness of apical clearing: Histological and radiographical evaluation. J Endod. 1994;20(5):219-224.

34. Wu MK, Wesselink PR. Efficacy of three techniques in cleaning the apical portion of curved root canals. Oral Surg Oral Med Oral Pathol Oral Radiol Endod. 1995;79(4):492-496.

35. Shuping GB, Orstavik D, Sigurdsson A, Trope M. Reduction of intracanal bacteria using nickeltitanium rotary instrumentation and various medications. J Endod. 2000;26(12):751-755.

36. Card SJ, Sigurdsson A, Orstavik D, Trope M. The effectiveness of increased apical enlargement in reducing intracanal bacteria. J Endod. 2002;28(11):779-783.

37. Rollison S, Barnett F, Stevens RH. Efficacy of bacterial removal from instrumented root canals in vitro related to instrumentation technique and size. Oral Surg Oral Med Oral Pathol Oral Radiol Endod. 2002;94(3):366-371.

38. Saini HR, Tewari S, Sangwan P, Duhan J, Gupta A. Effect of different apical preparation sizes on outcome of primary endodontic treatment: A randomized controlled trial. $J$ Endod. 2012;38(10):1309-1315.

39. Wu MK, Barkis D, Roris A, Wesselink PR. Does the first file to bind correspond to the diameter of the canal in the apical region? Int Endod J. 2002;35(3):264-267.

40. Jou YT, Karabucak B, Levin J, Liu D. Endodontic working width: Current concepts and techniques. Dent Clin North Am. 2004;48(1):323-335. 
41. Dillon JS, Amita, Gill B. To determine whether the first file to bind at the working length corresponds to the apical diameter in roots with apical curvatures both before and after preflaring. $J$ Conserv Dent. 2012;15(4):363-366.

42. Baugh D, Wallace J. The role of apical instrumentation in root canal treatment: A review of the literature. J Endod. 2005;31(5):333-340.

43. McGurkin-Smith R, Trope M, Caplan D, Sigurdsson A. Reduction of intracanal bacteria using GT rotary instrumentation, 5.25\% NaOCl, EDTA, and ca(OH)2. J Endod. 2005;31(5):359-363.

44. Siqueira JF,Jr, Rocas IN, Riche FN, Provenzano JC. Clinical outcome of the endodontic treatment of teeth with apical periodontitis using an antimicrobial protocol. Oral Surg Oral Med Oral Pathol Oral Radiol Endod. 2008;106(5):757-762.

45. Ram Z. Effectiveness of root canal irrigation. Oral Surg Oral Med Oral Pathol. 1977;44(2):306312.

46. Salzgeber RM, Brilliant JD. An in vivo evaluation of the penetration of an irrigating solution in root canals. J Endod. 1977;3(10):394-398.

47. Chow TW. Mechanical effectiveness of root canal irrigation. J Endod. 1983;9(11):475-479.

48. Usman N, Baumgartner JC, Marshall JG. Influence of instrument size on root canal debridement. J Endod. 2004;30(2):110-112.

49. Bierenkrant DE, Parashos P, Messer HH. The technical quality of nonsurgical root canal treatment performed by a selected cohort of australian endodontists. Int Endod J. 2008;41(7):561570.

50. Tan BT, Messer HH. The quality of apical canal preparation using hand and rotary instruments with specific criteria for enlargement based on initial apical file size. $J$ Endod. 2002;28(9):658-664. 
51. Darda S, Manwar N, Chandak M, Shori DD. An in vivo evaluation of two types of files used to accurately determine the diameter of the apical constriction of a root canal: An in vivo study. $J$ Contemp Dent Pract. 2009;10(4):43-50.

52. Souza RA, Dantas JC, Brandao PM, Colombo S, Lago M, Duarte MA. Apical third enlargement of the root canal and its relationship with the repair of periapical lesions. Eur J Dent. 2012;6(4):385388.

53. Albrecht LJ, Baumgartner JC, Marshall JG. Evaluation of apical debris removal using various sizes and tapers of ProFile GT files. J Endod. 2004;30(6):425-428.

54. Rocas IN, Lima KC, Siqueira JF,Jr. Reduction in bacterial counts in infected root canals after rotary or hand nickel-titanium instrumentation--a clinical study. Int Endod J. 2013;46(7):681-687.

55. Siqueira JF,Jr, Lima KC, Magalhaes FA, Lopes HP, de Uzeda M. Mechanical reduction of the bacterial population in the root canal by three instrumentation techniques. J Endod. 1999;25(5):332335.

56. Yared GM, Dagher FE. Influence of apical enlargement on bacterial infection during treatment of apical periodontitis. J Endod. 1994;20(11):535-537.

57. Aminoshariae A, Kulild JC. Master apical file size - smaller or larger: A systematic review of healing outcomes. Int Endod J. 2015;48(7):639-647.

58. Bystrom A, Sundqvist G. Bacteriologic evaluation of the efficacy of mechanical root canal instrumentation in endodontic therapy. Scand J Dent Res. 1981;89(4):321-328.

59. Buchanan LS. The standardized-taper root canal preparation--part 1. concepts for variably tapered shaping instruments. Int Endod J. 2000;33(6):516-529.

60. Brunson M, Heilborn C, Johnson DJ, Cohenca N. Effect of apical preparation size and preparation taper on irrigant volume delivered by using negative pressure irrigation system. $J$ Endod. 2010;36(4):721-724. 
61. Zuckerman O, Katz A, Pilo R, Tamse A, Fuss Z. Residual dentin thickness in mesial roots of mandibular molars prepared with lightspeed rotary instruments and gates-glidden reamers. Oral Surgery, Oral Medicine, Oral Pathology, Oral Radiology and Endodontology. 2003;96(3):351-355.

62. Stern N, Hirshfeld Z. Principles of preparing endodontically treated teeth for dowel and core restorations. J Prosthet Dent. 1973;30(2):162-165.

63. Johnson JK, Schwartz NL, Blackwell RT. Evaluation and restoration of endodontically treated posterior teeth. J Am Dent Assoc. 1976;93(3):597-605.

64. Tilk MA, Lommel TJ, Gerstein H. A study of mandibular and maxillary root widths to determine dowel size. J Endod. 1979;5(3):79-82.

65. Caputo AA, Standlee JP. Pins and posts--why, when and how. Dent Clin North Am. 1976;20(2):299-311.

66. Gluskin AH, Radke RA, Frost SL, Watanabe LG. The mandibular incisor: Rethinking guidelines for post and core design. J Endod. 1995;21(1):33-37. doi: S0099-2399(06)80554-6 [pii].

67. Schneider SW. A comparison of canal preparations in straight and curved root canals. Oral Surgery, Oral Medicine, Oral Pathology. 1971;32(2):271-275.

68. Weine FS, Kelly RF, Lio PJ. The effect of preparation procedures on original canal shape and on apical foramen shape. J Endod. 1975;1(8):255-262.

69. Abou-Rass M, Frank AL, Glick DH. The anticurvature filing method to prepare the curved root canal. J Am Dent Assoc. 1980;101(5):792-794.

70. Stewart JT, Lafkowitz S, Appelbaum K, Hartwell G. Distortion and breakage of liberator, EndoSequence, and ProFile systems in severely curved roots of molars. J Endod. 2010;36(4):729731. doi: 10.1016/j.joen.2009.11.029. 
71. Schäfer E, Florek H. Efficiency of rotary nickel-titanium K3 instruments compared with stainless steel hand K-Flexofile. part 1. shaping ability in simulated curved canals. Int Endod J. 2003;36(3):199-207.

72. Portenier, Lutz, Barbakow. Preparation of the apical part of the root canal by the lightspeed and step-back techniques. Int Endod J. 1998;31(2):103-111.

73. Glosson CR, Haller RH, Brent Dove S, del Rio CE. A comparison of root canal preparations using ni-ti hand, ni-ti engine-driven, and K-flex endodontic instruments. J Endod. 1995;21(3):146151.

74. Gergi R, Rjeily JA, Sader J, Naaman A. Comparison of canal transportation and centering ability of twisted files, pathfile-ProTaper system, and stainless steel hand K-files by using computed tomography. J Endod. 2010;36(5):904-907.

75. Bonaccorso A, Cantatore G, Condorelli GG, Schäfer E, Tripi TR. Shaping ability of four nickeltitanium rotary instruments in simulated S-shaped canals. J Endod. 2009;35(6):883-886.

76. You SY, Bae KS, Baek SH, Kum KY, Shon WJ, Lee W. Lifespan of one nickel-titanium rotary file with reciprocating motion in curved root canals. J Endod. 2010;36(12):1991-1994.

77. Varela-Patiño P, Ibañez-Párraga A, Rivas-Mundiña B, Cantatore G, Otero XL, Martin-Biedma B. Alternating versus continuous rotation: A comparative study of the effect on instrument life. J Endod. 2010;36(1):157-159.

78. Yared G. Canal preparation using only one Ni-Ti rotary instrument: Preliminary observations. Int Endod J. 2008;41(4):339-344.

79. Roane JB, Sabala CL, Duncanson MG,Jr. The "balanced force" concept for instrumentation of curved canals. J Endod. 1985;11(5):203-211.

80. Markvart M, Darvann TA, Larsen P, Dalstra M, Kreiborg S, Bjørndal L. Micro-CT analyses of apical enlargement and molar root canal complexity. Int Endod J. 2012;45(3):273-281. 
81. Yang G, Yuan G, Yun X, Zhou X, Liu B, Wu H. Effects of two nickel-titanium instrument systems, mtwo versus ProTaper universal, on root canal geometry assessed by Micro-Computed tomography. J Endod. 2011;37(10):1412-1416.

82. Zhao D, Shen Y, Peng B, Haapasalo M. Root canal preparation of mandibular molars with 3 nickel-titanium rotary instruments: A micro-computed tomographic study. J Endod. 2014;40(11):1860-1864.

83. Gergi R, Osta N, Bourbouze G, Zgheib C, Arbab-Chirani R, Naaman A. Effects of three nickel titanium instrument systems on root canal geometry assessed by micro-computed tomography. Int Endod J. 2015;48(2):162-170.

84. Paqué F, Zehnder M, De-Deus G. Microtomography-based comparison of reciprocating singlefile F2 ProTaper technique versus rotary full sequence. J Endod. 2011;37(10):1394-1397.

85. Siqueira JF,Jr, Alves FR, Versiani MA, et al. Correlative bacteriologic and micro-computed tomographic analysis of mandibular molar mesial canals prepared by self-adjusting file, reciproc, and twisted file systems. J Endod. 2013;39(8):1044-1050.

86. Bortoluzzi EA, Carlon D, Meghil MM, et al. Efficacy of 3D conforming nickel titanium rotary instruments in eliminating canal wall bacteria from oval-shaped root canals. J Dent. 2015;43(5):597604.

87. de Siqueira Zuolo A, Zuolo ML, da Silveira Bueno CE, Chu R, Cunha RS. Evaluation of the efficacy of TRUShape and reciproc File Systems in the removal of root filling material: An Ex Vivo micro-computed tomographic study. J Endod. 2016;42(2):315-319.

88. de Vasconcelos RA, Murphy S, Carvalho CA, Govindjee RG, Govindjee S, Peters OA. Evidence for reduced fatigue resistance of contemporary rotary instruments exposed to body temperature. $J$ Endod. 2016.

89. The internal anatomy of the teeth with special reference to the pulp with its branches. Dent Cosmos 1925;67:581-92 
90. Endodontic therapy. St. Louis: C.V. Mosby, 1972. pp. 164-239.

91. Grossman, L.I. Irrigation of root canals. The Journal of the American Dental Association, 1943;30(23):1915-1917.

92. Gluskin AH, Peters CI, Wong RD Ming, Ruddle CJ. Retreatment of non-healing endodontic therapy and management of mishaps. In: Ingle JI, Bakland LK, Baumgartner C, editors. Text book of Endodontics. 6th ed. Hamilton, Ontario, USA: BC Decker; 2008. pp. 1088-1161.

93. Hülsmann M, Peters OA, Dummer PM. Mechanical preparation of root canals: Shaping goals, techniques and means. Endo Topics. 2005;10:30-76.

94. American Association of Endodontists Glossary of Endodontic Terms. 9th ed. Chicago: AAE; 2016.

95. Young GR, Parashos P, Messer HH. The principles of techniques for cleaning root canals. Aust Dent J Endodontics. 2007;52(Suppl):S52-63 


\section{West VirginiaUniversity. Office of Research Integrity and Compliance}

\section{Acknowledgement Letter Not Human Subject Research NHSR}

To TakashiÂ Komabayashi

From WVU Office of Research Integrity and Compliance

Action Date 01/23/2015

Approval Period 01/23/2015 Expiration Date 01/22/2020

Subject Not Human Subject Research Acknowledgment

Protocol Number 1411494231

Title Apical canal transportation after instrumentation with 2 new rotary files using micro CT

Thank you for your submission to the West Virginia University Institutional Review Board IRB.

It has been determined that your project does not meet the definition of human subject research for the following reasons:

In order to be considered human subject research, individually identifiable private information must be obtained or used in the research. If there is no individually identifiable private information involved, the project is not human subject research and does not require being submitted to the Office of Research Integrity \& Compliance. Private information must be individually identifiable (i.e., the identity of the subject is or may be readily ascertained by the investigator or someone else associated with the information) in order to constitute research involving human subjects.

The Office of Research Integrity and Compliance is here to provide assistance to you from the initial submission of an IRB protocol to its approval and all subsequent activity. Please feel free to contact us by phone at304.293.7073 with any question you may have. Thank you.

WVU Office of Research Integrity and Compliance

Date: $01 / 23 / 2015$

Signed:

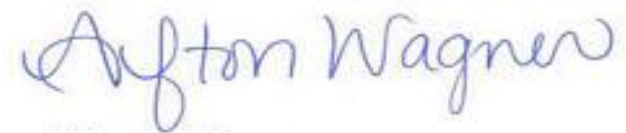

Afton Wagner IRB Administrator 


\section{Appendix}

\begin{tabular}{|c|c|c|c|c|c|c|c|c|c|}
\hline Tooth & Group & $\mathrm{X} 1$ & $\mathrm{x} 2$ & $\mathrm{Y} 1$ & $\mathrm{Y} 2$ & $\mathrm{x}$ & $\mathrm{Y}$ & Transportation & Centering Ratio \\
\hline 1 & 1 & 0.032 & 0.03 & 0.044 & 0.042 & 0.002 & 0.002 & 0 & 1 \\
\hline 2 & 1 & 0.038 & 0.029 & 0.048 & 0.044 & 0.009 & 0.004 & 0.005 & 0.44 \\
\hline 3 & 2 & 0.057 & 0.055 & 0.06 & 0.057 & 0.002 & 0.003 & 0.001 & 0.67 \\
\hline 4 & 2 & 0.049 & 0.04 & 0.047 & 0.045 & 0.009 & 0.002 & 0.007 & 0.22 \\
\hline 5 & 1 & 0.055 & 0.01 & 0.048 & 0.042 & 0.004 & 0.006 & 0.002 & 0.67 \\
\hline 6 & 1 & 0.04 & 0.032 & 0.044 & 0.042 & 0.008 & 0.002 & 0.006 & 0.25 \\
\hline 7 & 2 & 0.056 & 0.053 & 0.037 & 0.033 & 0.003 & 0.004 & 0.001 & 0.75 \\
\hline 8 & 2 & 0.032 & 0.031 & 0.028 & 0.028 & 0.001 & 0 & 0.001 & 0 \\
\hline 9 & 1 & 0.03 & 0.022 & 0.054 & 0.051 & 0.008 & 0.003 & 0.005 & 0.375 \\
\hline 10 & 1 & 0.03 & 0.03 & 0.048 & 0.041 & 0 & 0.007 & 0.007 & 0 \\
\hline 11 & 2 & 0.048 & 0.043 & 0.028 & 0.027 & 0.005 & 0.001 & 0.004 & 0.2 \\
\hline 12 & 2 & 0.034 & 0.034 & 0.03 & 0.028 & 0 & 0.002 & 0.002 & 0 \\
\hline 13 & 1 & 0.024 & 0.022 & 0.059 & 0.052 & 0.002 & 0.007 & 0.005 & 0.286 \\
\hline 14 & 1 & 0.023 & 0.022 & 0.033 & 0.03 & 0.001 & 0.003 & 0.002 & 0.33 \\
\hline 15 & 2 & 0.058 & 0.057 & 0.036 & 0.033 & 0.001 & 0.003 & 0.002 & 0.33 \\
\hline 16 & 2 & 0.048 & 0.04 & 0.035 & 0.028 & 0.008 & 0.007 & 0.001 & 0.857 \\
\hline 17 & 1 & 0.038 & 0.033 & 0.028 & 0.026 & 0.005 & 0.002 & 0.003 & 0.4 \\
\hline 18 & 1 & 0.045 & 0.044 & 0.026 & 0.022 & 0.001 & 0.004 & 0.003 & 0.25 \\
\hline 19 & 2 & 0.057 & 0.053 & 0.06 & 0.058 & 0.003 & 0.002 & 0.001 & 0.66 \\
\hline 20 & 2 & 0.044 & 0.043 & 0.054 & 0.051 & 0.001 & 0.003 & 0.002 & 0.33 \\
\hline 21 & 1 & 0.065 & 0.062 & 0.033 & 0.032 & 0.003 & 0.001 & 0.002 & 0.33 \\
\hline 22 & 1 & 0.053 & 0.052 & 0.049 & 0.04 & 0.001 & 0.009 & 0.008 & 0.11 \\
\hline 23 & 2 & 0.048 & 0.047 & 0.036 & 0.032 & 0.001 & 0.004 & 0.003 & 0.25 \\
\hline 24 & 2 & 0.056 & 0.051 & 0.029 & 0.029 & 0.005 & 0 & 0.005 & 0 \\
\hline 25 & 1 & 0.048 & 0.042 & 0.069 & 0.052 & 0.006 & 0.017 & 0.011 & 0.353 \\
\hline 26 & 1 & 0.038 & 0.034 & 0.029 & 0.028 & 0.004 & 0.001 & 0.003 & 0.25 \\
\hline 27 & 2 & 0.032 & 0.032 & 0.036 & 0.034 & 0 & 0.002 & 0.002 & 0 \\
\hline 28 & 2 & 0.049 & 0.043 & 0.037 & 0.035 & 0.006 & 0.002 & 0.004 & 0.33 \\
\hline 29 & 1 & 0.06 & 0.053 & 0.029 & 0.028 & 0.007 & 0.001 & 0.006 & 0.143 \\
\hline 30 & 2 & 0.045 & 0.044 & 0.047 & 0.043 & 0.001 & 0.004 & 0.003 & 0.25 \\
\hline
\end{tabular}

Table of values for Transportation and centering ratio using absolute values 